\title{
El crecimiento económico restringido por el equilibrio de la Balanza de Pagos: el caso de México'
}

\author{
Rogelio Madrueño Aguilar \\ Investigador Asociado del ICEI* y del COIBA
}

\begin{abstract}
Resumen
El artículo hace una revisión de la literatura reciente del crecimiento económico restringido por la Balanza de Pagos, destacando las principales aportaciones que se han derivado dentro de los modelos teóricos, así como las principales enseñanzas que se han obtenido dentro de los ejercicios econométricos empíricos en Latinoamérica. A partir de entonces se profundiza sobre las principales aplicaciones al caso mexicano, ofreciendo un balance de los principales resultados, las limitaciones analíticas, y las enseñanzas futuras para el análisis de la restricción externa al crecimiento de México.

Palabras clave: Comercio, restricción externa, crecimiento económico en economías abiertas, equilibrio externo, post-keynesianos, países en desarrollo, México.
\end{abstract}

Clasificación JEL: F14, F43, E12, O47.

\begin{abstract}
The article reviews the recent literature about the balance of payments constraint on economic growth. It highlights the main theoretical contributions and outcomes that have been obtained within the empirical econometric exercises of Latin American economies. Based on this, it shall analyse the main applications to the Mexican case, evaluating the results, analytical limitations and lessons for future studies.
\end{abstract}

Keywords: Trade, external constraint, economic growth of open economies, external equilibrium, developing countries, México.

JEL classification: F14, F43, E12, O47.

\section{Introducción}

La literatura que estudia el fenómeno de la restricción al crecimiento de la balanza de pagos subraya el problema del desequilibrio externo vinculado al proceso de desarrollo. De esta forma deja ver que en su naturaleza subyace el problema del cambio en las condiciones estructurales de la economía ante cambios en el entorno. Tradicionalmente los países de América Latina han tenido como principal restricción la brecha externa. Sin embargo, en un escenario de fuertes transformaciones en las últimas décadas resulta sugerente estudiar el estado actual del debate en la materia. En este sentido, el presente trabajo realiza una breve revisión de los enfoques de restric-

${ }^{1}$ El autor agradece los valiosos comentarios y sugerencias de José Antonio Alonso y Valpy Fitzgerald. Los posibles errores y omisiones son responsabilidad del autor.

* Instituto Complutense de Estudios Internacionales. 
ción al crecimiento, así como de las principales conclusiones a las que han arribado los estudios empíricos en la región latinoamericana y en México, a fin de conocer las enseñanzas y posibles líneas de investigación que pueden surgir para este último.

\section{La literatura sobre los modelos de crecimiento económico restringido}

Dentro de la literatura económica que no comparte plenamente el postulado de Say -intrínseco a la teoría del crecimiento convencional ${ }^{2}$ - destacan tres enfoques que resaltan las restricciones al crecimiento desde vertientes diferentes, aunque estrechamente vinculadas. En primer lugar encontramos las teorías que enfatizan las limitaciones de oferta como causantes de los cambios en el ingreso. Entre estos se encuentran los modelos con recursos limitados o restricciones sectoriales de oferta (Prebisch, 1959; Chenery y Bruno, 1962; Bacha, 1982, Taylor, 1994, entre otros). En segundo lugar, se ubican las teorías que resaltan el papel de la demanda desde el lado de la inversión, así como el ajuste macroeconómico de corto plazo vía el ahorro forzoso (Keynes, 1930; Schumpeter, 1934; Kaldor, 1957 y 1966; Thirlwall, 1979, entre otros). En una tercera línea están los factores institucionales que actúan como determinantes de los diferenciales del crecimiento y la generación de desequilibrios sectoriales (Véase esquema 1).

ESQUEMA 1

MARCO BÁSICO SOBRE LA EXPLICACIÓN
DEL CRECIMIENTO ECONÓMICO Y SUS RESTRICCIONES

\section{CRECIMIENTO ECONÓMICO PER CÁPITA:}

Enfoques de la restricción al crecimiento económico

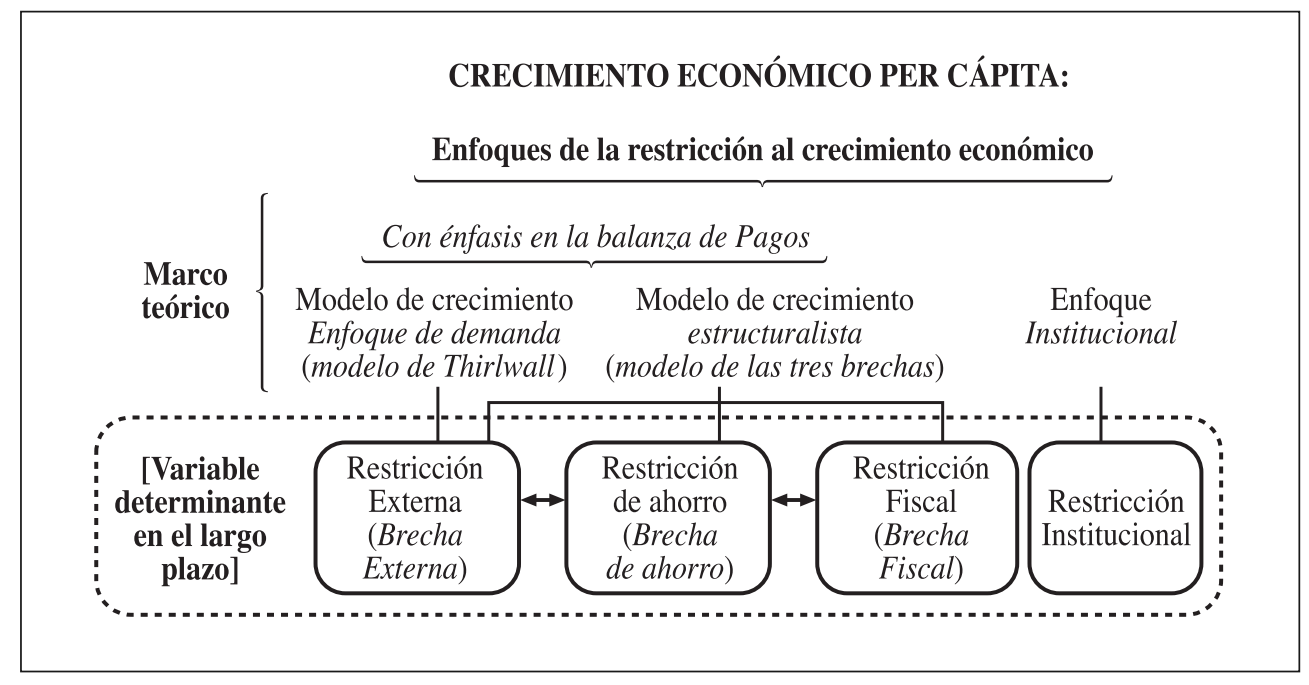

Fuente: elaboración propia.

${ }^{2}$ Para enmarcar este comentario, véase el artículo de Alonso en este mismo número. 
Este trabajo se centrará en los dos primeros enfoques, siendo consistente con la mayor atención que ha mantenido la literatura empírica del crecimiento -no enmarcada dentro de la corriente convencional- y que resaltan a su vez las restricciones impuestas por la balanza de pagos.

\subsection{Restricciones por recursos limitados: Los modelos de dos y tres brechas}

El planteamiento de la restricción al crecimiento que es originada por la dificultad que tienen los países para obtener divisas tiene su origen dentro de la CEPAL (1957) -Noyola, Urquídi, y Furtado- así como en Prebisch (1959), y atribuye su génesis a los desequilibrios estructurales de las economías en desarrollo. El análisis es formalizado por Chenery y Bruno (1962), Mckinnon (1964), así como Chenery y Strout (1966) mediante el desarrollo de los modelos de dos brechas, y es ampliado posteriormente por Taylor (1989 y 1994) y Bacha (1982 y 1990) con los denominados modelos de tres brechas. Su naturaleza se concibe como una forma de contrarrestar el argumento del modelo neoclásico de crecimiento que señala que el capital externo es un complemento del ahorro interno y contribuye a alcanzar un nuevo equilibrio que refleja una mayor relación capital-producto ${ }^{3}$.

El avance de los modelos de brechas ha sido amplio, desde los primeros desarrollos elaborados por Rostenstein-Rodan (1961), hasta la ampliación y aplicación de los trabajos de Chenery en los organismos financieros internacionales a través del modelo RMSM (Revised Minimun Standard Model) y su extensión al modelo RMSM-X del FMI, así como el del propio $\mathrm{BM}^{4}$.

Son modelos que resaltan que la tasa de crecimiento de una economía en desarrollo se encuentra limitada por la capacidad de generar ahorro, la disponibilidad de oferta de divisas, así como por la restricción fiscal. Consideran que en la dinámica de crecimiento se presentan fuertes desequilibrios que hacen difícil alcanzar estadios superiores dentro de la estrategia de sustitución de importaciones, principalmente por la dificultad de extenderla al sector de los bienes de capital. En este sentido, el ahorro se convierte en la principal restricción al crecimiento, especialmente en escenarios de fuerte ajuste macroeconómico (Taylor, 1996).

${ }^{3}$ Basado en un entorno de economía cerrada, perfecta movilidad de capitales, y sustitución de factores en donde la tasa de crecimiento de equilibrio viene dada por la tasa de cambio técnico -a la Harrod- y el la tasa de cambio de la fuerza laboral. Por su parte, los supuestos básicos de los modelos de brechas plantean que "hay un límite absoluto a la transformación de los bienes del país en importaciones (a través de las exportaciones)" y la necesidad de incorporar proporciones fijas de bienes nacionales e importados en la producción (Askari y Corbo, 1974, p. 22).

${ }^{4}$ Forman parte de los modelos que priorizan el ahorro y son base de los enfoques que dan fundamento a los programas de estabilización macroeconómica del Banco Mundial (BM) y el Fondo Monetario Internacional (FMI) (Pierre-Agénor, 2004; Fitzgerald, V. 2006). El primero sirve de base para las proyecciones macroeconómicas del Banco, en tanto el segundo integra el enfoque de programación financiera de ambas instituciones. 
Bacha (1982 y 1990) enfatiza que las brechas se encuentran en el ámbito interno y externo. ${ }^{5}$ De tal forma que incorpora a su análisis la brecha fiscal como una manera de reflejar la contradicción que supone al estimulo de la inversión y el crecimiento -determinado por el ingreso y los incentivos financieros-, la reducción del déficit fiscal -generando un efecto crowding-out-, así como el acceso a mayores flujos de ahorro externo ${ }^{6}$. El interés de Bacha (1990) es reflejar el entorno de ajuste estructural latinoamericano y de crisis sistemática de los años ochenta y principios de los noventa, que evidenció un deterioro de la inversión pública, al menos por tres canales:

(1) menores ingresos públicos resultado de la liberalización comercial,

(2) mayor peso de la deuda pública sobre los ingresos fiscales, y

(3) recursos fiscales limitados vinculados con las deficiencias de los esquemas tributarios.

En suma, la motivación inicial de estos modelos es mostrar las fuertes restricciones que experimentan las economías en tres ámbitos: la relación ahorro-inversión, el sector externo y el sector fiscal -principalmente en los países con altos niveles de deuda-, conformándose una tríada que es determinante para marcar la trayectoria de crecimiento. Por su parte, la principal crítica al enfoque se basa en su análisis de asignación estática, así como en las simulaciones económicas que se derivan de este supuesto. A pesar de ello, las implicaciones más relevantes dentro de su vertiente más reciente son la estrecha relación que puede existir entre los shocks externos y los desajustes financieros domésticos -elemento fundamental para la dinámica de recuperación y el crecimiento. Esto implica que la búsqueda de la solidez fiscal acompañada de la reducción de la inflación se convierten en un objetivo central de la política económica. No obstante, evitar desplazar la inversión privada en un entorno de estabilidad económica no es suficiente para relajar la restricción externa por lo que son necesarias políticas de acompañamiento que estimulen el crecimiento, entre las que se encuentran una adecuada inserción internacional, así como una captación de transferencias externas más eficaz.

\subsection{Modelizaciones desde la demanda}

La tradicional línea de argumentación de la automaticidad del ajuste externo, sin costes para el crecimiento, tiene una impronta marcadamente pre-keynesiana. En una

\footnotetext{
${ }^{5}$ El modelo de tres brechas comprende un ejercicio de maximización de la inversión, en condiciones de estabilidad de precios. El análisis está sujeto a relaciones de igualdad y desigualdad y busca medir el impacto de las transferencias externas en el crecimiento. Asimismo, asume diferentes supuestos de acuerdo al número de restricciones y las acciones de política económica.

${ }^{6}$ En este sentido, los efectos crowding-in y crowding-out entre inversión pública y privada dependerán de las diferentes combinaciones para determinar su carácter complementario o excluyente en relación con el nivel de inflación existente.
} 
economía abierta, los ajustes de precios y los movimientos del tipo de cambio son los encargados de promover este comportamiento, asumiendo plenamente la capacidad de producción de pleno empleo y una competencia perfecta. Si se relajan estos supuestos, el papel de la demanda se hace más relevante, considerando su papel impulsor en el proceso de inversión y crecimiento, al fomentar una mayor utilización de capacidad ociosa en la economía.

De esta forma, existe una relación bidireccional entre el crecimiento de la demanda y el aumento de la productividad (Young, 1928) que ha allanado el camino para los estudios que enfatizan la importancia de la demanda en la economía (Dixon y Thirlwall, 1975; Boyer y Petit, 1989 y 1991; Mc Combie y Thirlwall, 1994 y 2001, Kaldor, 1996, entre otros). Esta literatura económica busca explicar las diferentes tasas de crecimiento económico en la economía mundial, dada la existencia de diversos procesos de ajuste entre la oferta y la demanda correspondientes a cada nivel de ingreso. También supone que dentro de un proceso dinámico y acumulativo la demanda no restringe plenamente el crecimiento económico, manteniendo cierto grado de autonomía. Estas características han sido vinculadas con el sector externo, especialmente con las exportaciones, a través de varios efectos, a saber: su contribución a la ampliación de la producción nacional, la capacidad de relajar la restricción externa de la balanza de pagos, así como mejorar el progreso técnico y la productividad ${ }^{7}$ (Alonso, 1996).

El enfoque post-keynesiano de la restricción externa al crecimiento económico (REC) se centra en analizar la relación entre el crecimiento y el equilibrio externo, a fin de determinar la tasa de crecimiento compatible con el equilibrio de la balanza de pagos. Considera en un primer momento la evolución de la cuenta corriente, principalmente a través la balanza corriente (Thirlwall, 1979) ${ }^{8}$ y en un segundo, su ampliación a los flujos de capital (Thirlwall y Hussein, 1982) ${ }^{9}$. En este marco de análisis, el sector externo es un elemento central para las posibilidades de crecimiento de una economía bajo el supuesto de que la tasa de crecimiento nacional viene determinada por la dinámica del mercado externo, el valor de las elasticidades ingreso asociadas al comercio, al tiempo que asume una influencia limitada de los precios relativos en el ajuste de la balanza de pagos ${ }^{10}$.

En Harrod (1933) se encuentra la génesis de este enfoque en su versión del multiplicador estático del comercio exterior (McCombie y Thirlwall, 1993). Posterior-

${ }^{7}$ A través de la llamada Ley de Verdoorn perteneciente a la tradición del modelo de causación circular acumulativa de Myrdal (1957).

${ }^{8}$ Se parte de la base de considerar que en una economía abierta lo relevante es el equilibrio en la balanza comercial, aunque en esencia de acuerdo con el enfoque intertemporal de la balanza de pagos realizado por Sachs (1981), la diferencia entre ahorro e inversión sigue reflejando el saldo en cuenta corriente. [A pesar de que el enfoque intertemporal de la BCC forma parte del enfoque neoclásico, el criterio de equilibrio que utiliza es la igualdad entre ahorro e inversión, tal como lo planteó Keynes en su explicación para una economía cerrada].

${ }_{9}$ Véase también Moreno-Brid (1999).

${ }^{10}$ Se asume que en el largo plazo se cumple la paridad del poder de compra, por lo que existe estabilidad de precios relativos. A ellos se suman los nuevos factores asociados a la fijación de los precios en los mercados internacionales (Alonso y Garcimartín, 1999). 
mente Thirlwall (1979) retoma esta idea para elaborar su modelo que supone el equilibrio de la balanza comercial $X P=M P^{* 11}$ en el largo plazo. El modelo básico plantea dos funciones agregadas de comercio:

$$
\begin{aligned}
& X_{t}=A_{t} *\left(\frac{P_{d t}}{P_{f t}^{*}}\right)^{\gamma} y_{t}^{* \varepsilon} \\
& M_{t}=B_{t} *\left(\frac{P_{f t}}{P_{d t}^{*}}\right)^{\eta} y_{t}^{\pi}
\end{aligned}
$$

Donde A y B son las constantes en cada función de demanda, $y$ la renta nacional, $y^{*}$ la renta mundial, $\gamma$ la elasticidad precio de las exportaciones, $\eta$ la elasticidad precio de las importaciones. En tanto que $\varepsilon$ y $\pi$ son las elasticidades renta de las ventas externas y las compras externas, respectivamente.

La ecuación de la tasa de crecimiento de la producción compatible con el equilibrio de balanza de pagos se obtiene después de haber expresado las funciones de comercio en su versión dinámica ${ }^{12}$.

Esto es,

$$
\dot{y}_{e t}=\frac{(1+\gamma+\eta)\left(\dot{p}_{d t}-\dot{p}_{f t}\right)+\varepsilon \dot{y}_{t}^{*}}{\pi}
$$

De tal forma que la tasa de crecimiento de la economía $\left(y_{e}\right)$ en el largo plazo será consistente con el equilibrio en la balanza de pagos $\left(y_{b}\right)$. La denominada ley de Thirlwall indica que la balanza de pagos impone la restricción al crecimiento, a través del límite impuesto por la disponibilidad de divisas en la economía. El modelo señala que una economía puede prescindir de la primera parte de la ecuación, una vez que se asume que las elasticidades precio son próximas a cero, en tanto que el diferencial de tasas de crecimiento es corregido por el tipo de cambio, es decir, $(1+\gamma+\eta) \approx 0$. Por tanto, el crecimiento de la renta compatible con el equilibrio externo depende de la dinámica de la producción global y del cociente de elasticidades renta de las funciones de comercio:

$$
\dot{y}_{e t}=\frac{\varepsilon \dot{y}_{t}^{*}}{\pi}
$$

${ }^{11} \mathrm{X}$ y $\mathrm{M}$ representan los volúmenes de exportaciones e importaciones y $\mathrm{P}$ y $\mathrm{P}^{*}$ son los niveles de precios domésticos y externo, ambos expresados en una moneda común.

${ }_{12}$ Tomando logaritmos y derivando respecto al tiempo. Por su parte, el punto sobre una variable representa su tasa de variación en el tiempo. 
Arribar a esta conclusión no ha estado exenta de un amplio debate, principalmente por las consideraciones relativas a la competencia imperfecta, presentes en los mercados internacionales (Mc Gregor y Swales, 1985, 1986 y 1991; Thirlwall, 1986; McCombie, 1989, McCombie y Thirlwall, 1994). El hecho de que el modelo no capte esta peculiaridad y asuma la neutralidad de los precios relativos ha sido subrayado como una debilidad intrínseca a la explicación de la restricción desde el lado de la demanda. Dentro de esta controversia se han esgrimido dos tipos de argumentos. Por un lado, los que consideran que en el largo plazo las modificaciones en los precios relativos no son significativas, dado que el modelo ya incorpora la composición de las exportaciones y, por ende, los elementos relativos a la competencia imperfecta. En el extremo opuesto se ubican los que enfatizan que es necesario introducir elementos adicionales en el modelo que den cuenta del cambio en la composición de la oferta a lo largo del tiempo (Alonso y Garcimartín, 1999; Dutt, 2002).

Dentro de los primeros, los estudios de Mc Combie (1993), Bairam (1988) y Blecker (1998) aglutinan los esfuerzos que respaldan la validez de la ley de Thirlwall en un contexto de interdependencia comercial, además de que proveen conclusiones relevantes sobre la necesidad de instrumentación de políticas macroeconómicas coordinadas a nivel internacional. La ampliación que realiza McCombie (1993) del modelo básico de Thirlwall se da en el marco de un modelo dinámico de interdependencia comercial global que subraya las restricciones al crecimiento impuestas entre países. En este marco, uno de los argumentos centrales indica que si bien la implementación de políticas comerciales ayudan a relajar la REC -v. gr. devaluación del tipo de cambio- sólo servirán de estimulo en el corto plazo, ya que a la larga no afectan que la tasa de crecimiento sea consistente con el equilibrio de balanza de $\mathrm{Pa}$ gos (Perrotini, 2003).

Cabe destacar como un aspecto polémico la interpretación de convergencia condicional que se deriva del modelo, la cual aparece cuando la ratio $(\varepsilon / \pi)$ de los países de menor renta per capita es superior a la de los países desarrollados (Alonso y Garcimartín, 1999). Este aspecto tampoco ha estado exento de crítica considerando la evidencia empírica de impulsos relativamente breves en el crecimiento (Haussman et al, 2005).

A lo largo del tiempo, los defensores de este enfoque de demanda han tratado de subsanar las debilidades del modelo de diversos modos. En primer lugar se amplió el arco de análisis inicial a fin de introducir otros componentes de la cuenta corriente y poder captar los fuertes desequilibrios de balanza de pagos que experimentan algunas naciones. El modelo de Thirlwall y Hussein $(1982,1994)$ estudia los desequilibrios en cuenta corriente y la restricción al crecimiento a través de los flujos netos de capital. Para estos autores, contar con desequilibrios en cuenta corriente no imposibilita a los países en desarrollo generar flujos sostenidos de capital que ayuden a cerrar la brecha externa y provocar ritmos de crecimiento acelerado. Siguiendo en esta línea, Moreno-Brid (1998 y 2003) profundiza el análisis resaltando la necesidad de considerar el papel negativo que desempeña la deuda externa. De tal forma que en su adaptación la tasa de crecimiento sostenible será aquella que permita tener 
un saldo constante de la balanza en cuenta corriente en términos relativos respecto del PIB. Es decir, aquella que permita la sostenibilidad de los flujos netos de capital en el patrón de crecimiento.

En el segundo grupo de argumentos se encuentran los que abogan por la inclusión de elementos de oferta en la ecuación de restricción externa. Su planteamiento es sugerente, ya que subraya la importancia de los shocks de oferta. La literatura de la ley Thirlwall ha tenido una amplia gama de aplicación empírica y logra explicar en muchos de los casos la trayectoria de crecimiento de largo plazo de los países inmersos en su análisis. Sin embargo, no lo ha conseguido plenamente en aquellos que han experimentado fluctuaciones en los términos de intercambio y en la posición de su balanza de pagos (Dutt, 2002). En este sentido, la realidad internacional muestra que en los últimos años un amplio grupo de países en desarrollo han experimentado una restricción externa dominante impuesta por un entorno macroeconómico adverso que ha terminado por afectar su desempeño económico (Ffrench-Davis, 2005). Esto implica, como lo hace Alonso (1999), considerar la inclusión en las funciones de comercio, primordialmente en las exportaciones, de elementos que consideren las transformaciones en la composición y calidad de la oferta a lo largo del tiempo, lo que ayudaría a corregir el posible sesgo.

Con la finalidad de compatibilizar el modelo de Thirlwall con la idea de la convergencia, Alonso y Garcimartín (1998 y 999) consideran la incorporación de aspectos comunes a ésta, como son el esfuerzo tecnológico y los procesos de difusión tecnológica. Es así como se establecen las funciones de comercio que siguen la tradición del modelo de Thirlwall, aunque con la única variante de incluir el papel del esfuerzo innovador del país $(\Omega)$, así como el proceso de difusión tecnológica entre el país seguidor y el país líder $\left(\hat{y}_{s}-\hat{y}_{l}\right)$. De esta forma, las nuevas funciones de comercio estarían dadas por:

$$
\begin{gathered}
\dot{x}_{t}=\gamma\left(\dot{p}_{d t}-\dot{p}_{f t}\right)+\varepsilon \dot{y}_{t}^{*}+\Omega_{1} \dot{\tau}+\psi_{1}\left(\hat{y}_{s}-\hat{y}_{l}\right) \\
\dot{m}_{t}=\eta\left(\dot{p}_{f t}-\dot{p}_{d t}\right)+\pi \dot{y}_{t}+\Omega_{2} \dot{\tau}+\psi_{2}\left(\hat{y}_{s}-\hat{y}_{l}\right) \\
\gamma<0, \quad \eta<0, \quad \Omega_{1}>0, \quad \Omega_{2}<0, \quad \psi_{1}<0, \quad \psi_{2}>0
\end{gathered}
$$

Con ello plantean la posibilidad de un proceso de convergencia, dominantemente condicionada por la dinámica de difusión del cambio técnico. Los autores asumen una serie de supuestos que les permite llegar a la siguiente ecuación reducida ${ }^{13}$.

$$
\hat{y}_{e t}=\hat{y}_{t}(0)+\lambda_{\hat{y} l} t \frac{\left(\Omega_{1}-\Omega_{2}\right) \dot{\tau}}{\left(\psi_{1}-\psi_{2}\right)}-\frac{(\varepsilon-\pi)}{\left(\psi_{1}-\psi_{2}\right)} \dot{y}^{*}
$$

${ }^{13}$ Se asumen precios relativos estables en el largo plazo, tasa de crecimiento del país líder igual a la tasa de crecimiento mundial, así como igualdad en las tasas de crecimiento de la población entre la economía líder y la de estudio. 
En este marco, el estado estacionario estará influido por el esfuerzo tecnológico del país, así como del proceso de difusión de la tecnología en el entorno. La influencia de ambas en las funciones de comercio determinará si una economía es susceptible de situarse en una posición de convergencia.

En suma, el tratamiento que ha recibido la defensa tradicional del enfoque de demanda sigue suscitando controversia, principalmente por sus implicaciones en la dinámica de convergencia y el supuesto en el que descansa -la estabilidad en la ratio de elasticidades renta de exportaciones e importaciones. La evidencia empírica internacional muestra en las últimas décadas impulsos breves en el crecimiento, además de fuertes procesos de ajuste que ponen en duda las prescripciones de este modelo, principalmente para los países en desarrollo. En este sentido, los avances recientes si bien subrayan la relevancia del papel de la demanda en el crecimiento ${ }^{14}$, no niegan la necesidad de incluir en el análisis de la restricción externa elementos de oferta que den cuenta del efecto conjunto de ambas variables sobre la dinámica de crecimiento económico.

\section{Estimaciones empíricas de los modelos de crecimiento restringido por la Balanza de Pagos en Latinoamérica}

Los estudios de crecimiento económico restringido por la Balanza de Pagos se han estimado por medio de diferentes técnicas econométricas. Los modelos de brechas han utilizado tradicionalmente el sistema de ecuaciones simultáneas, a fin de determinar las relaciones de equilibrio entre los requerimientos domésticos, externos y fiscales, y a partir de entonces obtener las brechas correspondientes: ahorro-inversión, externa y fiscal. En este marco, existe una importante literatura enfocada a estudiar el papel de la ayuda internacional y su impacto en el desarrollo. Está tarea inicia con los trabajos pioneros de Chenery y Strout $(1966)^{15}$ en su modelo de dos brechas. ${ }^{16}$

En el marco de los trabajos que no se centran en estudiar el impacto de la ayuda encontramos aplicaciones empíricas a partir de las derivaciones teóricas de Taylor (1989) y Bacha (1990). Entre ellas se destaca el análisis coordinado por Taylor (1991) que tiene entre sus principales conclusiones la necesidad de instrumentar políticas de condonación de la deuda para los países latinoamericanos como una manera de impulsar un nivel de crecimiento económico capaz de superar el impacto recesivo de la década de los ochenta, así como la difícil perspectiva de atracción de capitales de

14 A través de la influencia de la composición sectorial en el impulso económico, o bien en las restricciones al crecimiento que surgen por procurar mantener el equilibrio externo y/o la subutilización de la capacidad instalada. (Garcimartín, 2008).

${ }^{15}$ En este trabajo se hace referencia a los siguientes países latinoamericanos: Argentina, Bolivia, Brasil, Chile, Colombia, Costa Rica, Ecuador, El Salvador, Guatemala, Honduras, Jamaica, Mexico, Nicaragua, Panamá, Paragua, Perú, Trinidad-Tobago y Venezuela.

${ }^{16}$ Existe una amplia literatura al respecto que se ha ido adaptado y ampliando a técnicas econométricas más recientes. Para una revisión del tema véase Tezanos et al. (2009). 
los años noventa. Otros análisis similares -algunos con una perspectiva más nacional- ${ }^{17}$ muestran que los efectos de la implementación de los programas de estabilización económica en la región latinoamericana, durante la denominada década pérdida, supusieron la reducción del déficit fiscal, más no así del déficit externo, resaltando la añeja problemática estructural en estas economías. Al tiempo, se muestra como este fenómeno ha convivido con un incremento en los niveles de deuda privada que también han limitado el crecimiento de largo plazo (Barbosa-Filho et al., 2006). ${ }^{18}$ Finalmente, Suzuki (2008) -mediante un análisis de dos brechas realizado con la técnica de datos de panel- confirma que la región latinoamericana ha estado mayormente restringida en su brecha externa. Con ello se afirma que si bien este problema no es una limitante como lo fue durante la década de los setenta y ochenta han surgido problemas recientes que impactan a estas economías, como son: las fricciones financieras operando en los mercados de capital. En consecuencia, se subraya que el nuevo horizonte tampoco contribuye a una mejor inserción de los países latinoamericanos en la economía global.

En lo que respecta a las estimaciones que se han centrado en el modelo de Thirlwall, la literatura es abundante para los países en desarrollo. En el caso de los estudios para la región latinoamericana han sido estimados en su mayoría mediante análisis de regresión múltiple utilizando las técnicas de sección cruzada y de series temporales con análisis de vectores autoregresivos, cointegración y modelos de corrección de errores. Recientemente empiezan a ser utilizadas técnicas de datos en panel aunque de una manera muy incipiente. En el anexo 2 de este trabajo se presenta un resumen de los principales estudios para América Latina y el Caribe.

En conjunto, los estudios centrados en contrastar la REC de la región ofrecen un balance global bastante cohesionado en torno al impacto que tienen la elasticidad ingreso de la demanda de importaciones, la dinámica de las exportaciones, y la dinámica del mercado externo en la determinación de la tasa de crecimiento consistente con el equilibrio en Balanza de Pagos. Prácticamente todos los estudios confirman la eficacia de la denominada Ley de Thirlwall para explicar los periodos de análisis. De los datos se desprende que ha habido en las últimas décadas un deterioro en la restricción externa en las mayores economías con excepción de algunos países como Chile y en algunos periodos Venezuela. (Guerrero, 2004; Pacheco y Thirlwall, 2006). La experiencia generalizada es el incremento sustancial de la elasticidad ingreso de la demanda de importaciones posterior a la liberalización comercial y un proceso de desindustrialización.

${ }^{17}$ Entre los que se encuentran Solimano (1990) (Chile), Fanelli y Frenkel (1989) (Argentina) y Rozenwurcel y Visintini (1990) (Argentina), Dominioni y Licandro (1988) (Uruguay), Carneiro y Werneck (1989) (Brasil), Villar y Ocampo (1990 (Colombia), y Lora (1992) (Colombia), Romaguera y Contreras (1992) (Chile).

${ }^{18}$ El estudio de Belloc y Vertova (2004) muestra un resumen de la principal evidencia empírica sobre la hipótesis del efecto crowding-in versus crowding-out en la economía. Para el caso latinoamericano se indica que la inversión pública doméstica genera un efecto crowding-in sobre la inversión privada. 
Existe, sin embargo, un desacuerdo respecto al rol que tiene el tipo de cambio, los flujos netos de capital y las fricciones del lado de la oferta. Si bien, en algunos estudios se considera el papel positivo que éstos elementos pueden llegar a tener en la determinación de la tasa de crecimiento, no son incluidos en las estimaciones. Este elemento no deja de ser interesante, aun cuando pueden llegar a explicar con mayor certeza el sesgo en las desviaciones existentes entre la senda de crecimiento de largo plazo y la que es compatible con el equilibrio externo de la balanza de pagos (ver cuadro A1).

\section{El crecimiento económico restringido por Balanza de Pagos: El caso de México}

En tres décadas, la economía mexicana ha experimentado un cambio radical. Pasó de ser una economía prácticamente cerrada a convertirse en un país con una amplia red de Tratados de Libre Comercio y Acuerdos de Promoción de Inversiones. Este largo proceso inicia posterior a la crisis de la deuda en 1982 cuando emerge un sólido proceso de cambio estructural y liberalización económica que ha modificado el papel de las relaciones económicas internacionales de México. Como consecuencia, el sector externo adoptó un papel preponderante, aumentando el peso del comercio en la economía a niveles cercanos a 60 por ciento del PIB, a partir de 1994. Un momento crucial en la liberalización económica se da con el acceso al GATT en 1986 y su consolidación con la firma del NAFTA en 1994, ya que comprenden una serie de cambios sucesivos no sólo en términos comerciales y de inversión, sino también en términos institucionales que han transformado las estructuras internas del país.

La política económica de México y la estrategia de inserción global permitieron en sus etapas iníciales un rápido proceso de recuperación económica tras la crisis de 1994, así como una mayor correlación con la dinámica económica de EE.UU. Desde 2001, las decepciones en el impulso del crecimiento económico en México contienen un fuerte componente externo, asociado a la evolución del vecino del norte. Al tiempo, que se observan cuellos de botella a nivel interno para contrarrestar tal dinámica. Como consecuencia, se ha presentado una reducción progresiva de la dinámica de crecimiento, situándola por debajo del nivel potencial (Urquidi, 2005; Loría, 2003).

Una manera diferente de enfocar este fenómeno es mediante la observación de la evolución de la balanza comercial de bienes y servicios como porcentaje del PIB versus la tasa de crecimiento del producto nacional, así como contrastar esta misma dinámica con la influencia del PIB de EE.UU en el crecimiento de México. En ambos casos se observa la presencia del desequilibrio externo, ligeramente acentuado por la recuperación económica del lustro 1990-1994 (Gráfico 1). Sin embargo, a diferencia de ese periodo donde el nivel de déficit en la cuenta corriente externa creció fuertemente -aspecto que contribuyó al desenlace de la devaluación cambiaria de 1994- en los últimos años el déficit permanece oculto, en un entorno de bajo creci- 
miento económico, elevado ritmo de los ingresos de exportación -resultado de los altos precios del petróleo-, así como de la entrada de divisas vía las remesas de trabajadores emigrantes. Cabe mencionar que estos dos últimos elementos han perdido dinamismo de cara a la crisis iniciada en 2008 por lo que la trampa de crecimiento bajo se ha agudizado.

\section{GRÁFICO 1}

\section{BALANCE EXTERNO EN MÉXICO Y CRECIMIENTO DEL PIB}
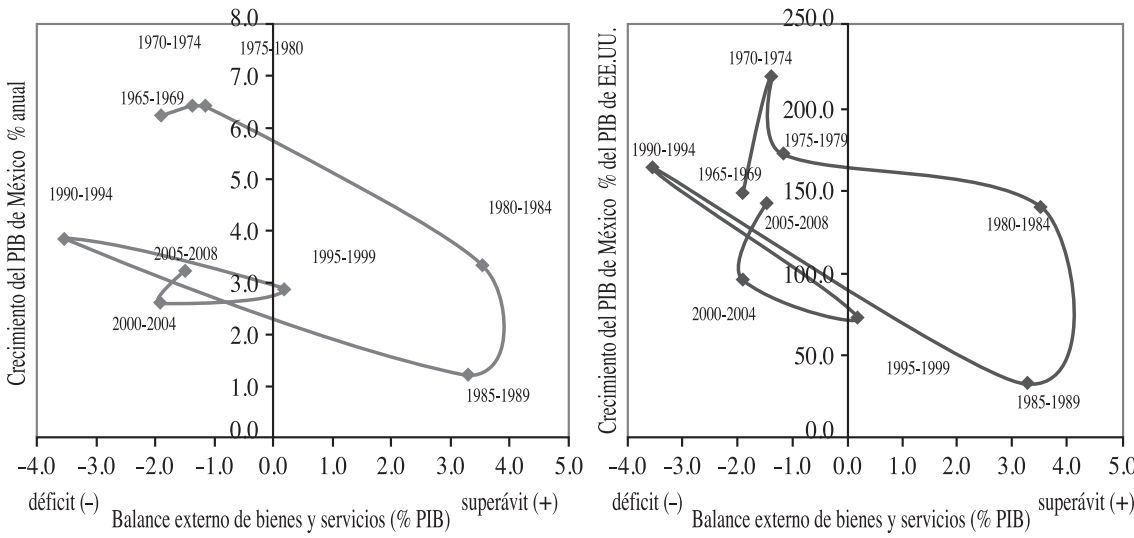

Fuente: WDI (2008) y Banco de México. Cálculos propios del autor.

En este marco se insertan las principales estimaciones de la restricción al crecimiento en México. El balance de las estimaciones se puede agrupar en tres niveles. El primero, en el marco de las estimaciones del modelo de brechas, se destaca el cambio en las características del desequilibrio macroeconómico. A inicios de los ochenta se presentaba básicamente como un problema de déficit gemelos: externo y fiscal, mientras que hacia 1995 el énfasis se concentró en la brecha de divisas y la de ahorro, después de una política de ajuste en las cuentas fiscales (Villareal, 2005). En este sentido, la estrategia gubernamental se insertó en un modelo que pone énfasis en la dependencia de mayores flujos externos para cubrir las necesidades de crecimiento y la brecha externa (Taylor, 2001). Asimismo, las estimaciones correspondientes al modelo de demanda de Thirlwall se adhieren a esta argumentación, con cierto grado de consenso sobre el papel creciente de la elasticidad ingreso de las importaciones y la falta de un crecimiento paralelo del lado de las exportaciones. Ambos, ejercen presión sobre la restricción externa, de tal forma que existe un trade off permanente entre crecimiento y balance externo sobre el que subyace el agotamiento y cambio del modelo de industrialización. (Moreno-Brid, 1998, 1999 y 2001). 
El segundo nivel de estimaciones se adentra en el análisis de las características sectoriales de la industria mexicana. Aquí se confirma la elevada elasticidad ingreso de la demanda de importaciones de las principales industrias en el periodo posterior a la apertura económica. Este rápido crecimiento de las importaciones no se ha traducido en mejoras de las condiciones estructurales de la balanza comercial. Por el contrario, existe un marcado incremento de los coeficientes de importación en las ramas exportadoras exitosas, a pesar del fuerte cambio en la estructura exportadora hacia bienes manufacturados. Como consecuencia, la oferta neta de divisas sigue centrada en exportaciones de petróleo y otros productos primarios de bajo valor agregado, además de los ingresos que se obtienen de las remesas de migrantes.

En el tercer nivel aparecen estimaciones que involucran características muy particulares de los países en desarrollo, y específicamente de la región latinoamericana, como son el papel de los flujos netos de capital y el movimiento del tipo de cambio. Se muestra que el pago de intereses externos ha sido determinante para condicionar el crecimiento económico de largo plazo de México. Además existe una evidencia favorable del modelo post-keynesiano con respecto al impacto positivo de los flujos de capital externo en el crecimiento aunque con un impacto reducido.

En nuestro caso, siendo consistentes con la revisión de literatura, se ha realizado un ejercicio preliminar que permita mostrar el efecto de otras variables que son pertinentes al caso mexicano. En este sentido, siguiendo la metodología post-keynesiana resulta apropiado estudiar el efecto que tiene la Inversión Extranjera Directa (IED) en las funciones de comercio, considerando las características que la vinculan con el modelo de industrialización orientado a las exportaciones emprendido por México. El periodo de estudio comprende los años 1980-2007 con información disponible en términos trimestrales. El objetivo es analizar la gestación del cambio de modelo de la economía mexicana en los ochenta, la profundización del cambio estructural y la etapa post-NAFTA.

De esta forma, el volumen de las exportaciones y las importaciones pueden ser expresados en su versión dinámica. Las variables en minúsculas expresan tasas de crecimiento:

$$
\begin{aligned}
& \dot{x}_{t}=\gamma\left(\dot{p}_{d t}-\dot{p}_{f t}-e_{t}\right)+\varepsilon \dot{z}_{t}+\sigma \dot{f}_{t} \\
& \dot{m}_{t}=\eta\left(\dot{p}_{f t}+\dot{e}_{t}-\dot{p}_{d t}\right)+\pi \dot{y}_{t}+v f_{t}
\end{aligned}
$$

Donde $P d$ y $P f$ son los precios nacionales e internacionales, $e$ es el tipo de cambio, $z$ es el ingreso mundial, $y$ es la renta nacional, $f$ mide la inversión extranjera directa, $\gamma$ y $\eta$ son las elasticidades de los precios en la funciones de comercio, mientras que $\varepsilon$ y $\pi$ son las elasticidades de los ingresos de las exportaciones y las importaciones. Finalmente $\sigma$ y $v$ son las elasticidades correspondientes a la IED. Las funciones de comercio ampliadas a la inclusión de la IED fueron estimadas a través de un modelo log-lineal y cumplen con el requisito de formar parte de un vector de cointegración. Las variables son significativas aplicando el mecanismo de corrección de errores en cada una de las ecuaciones (Cuadro 1). 


\section{CUADRO 1}

FUNCIONES DE COMERCIO (INCLUSIÓN DE IED)

\begin{tabular}{|c|c|c|c|}
\hline \multicolumn{4}{|c|}{ Función de exportaciones } \\
\hline & $\gamma$ & $\varepsilon$ & $\sigma$ \\
\hline Valor & -0.12 & 4.05 & 0.04 \\
\hline t-ratio & (11.48) & $(35.21)$ & $(2.38)$ \\
\hline \multicolumn{4}{|c|}{$\mathrm{R} 2=0.98 \quad \mathrm{DW}=1.95$} \\
\hline \multicolumn{4}{|c|}{ Función de importaciones } \\
\hline & $\gamma$ & $\varepsilon$ & $v$ \\
\hline Valor & 0.09 & 3.12 & 0.13 \\
\hline t-ratio & $(7.42)$ & $(18.53)$ & $(4.02)$ \\
\hline \multicolumn{4}{|c|}{$\mathrm{R} 2=0.97 \quad \mathrm{DW}=2.25$} \\
\hline
\end{tabular}

Fuente: elaboración propia.

Asimismo se analizó la influencia conjunta de la IED y las remesas de migrantes en la relajación de la restricción externa al crecimiento. Como es sabido, ambas variables son consideradas como elementos fundamentales de la economía mexicana, al atribuírseles un impacto favorable como fuentes de financiación externa. Para ello, en la primera etapa del trabajo, se efectuó un análisis de tendencia y determinación del orden de integración de las variables involucradas en el modelo. Se utilizaron las pruebas Dickey-Fuller Aumentada, Phillips-Perron, Sargan-Bhargava y Schmidt-Phillips. Los resultados mostraron que las series son estacionarias en primeras diferencias (Cuadro 2) ${ }^{19}$. Posteriormente se estimaron por medio del procedimiento de Johansen los modelos VAR correspondientes para el modelo tradicional de Thirlwall, así como para el modelo ampliado a la inclusión del efecto de la IED y las remesas en la ecuación de crecimiento correspondiente al equilibrio externo (Cuadro 3).

De esta forma, se observa que existe al menos un vector de cointegración, por lo que se confirma la pertinencia del modelo especificado. Los resultados muestran que existe una relación de largo plazo para las variables involucradas en los dos modelos. En el primer caso, el cociente de elasticidades renta fue de 1.04 con una elasticidad demanda de las importaciones de $2.61^{20}$. Como consecuencia, el crecimiento

${ }^{19}$ En el cuadro sólo se muestran los resultados de la primera prueba.

${ }^{20}$ La elasticidad es calculada por medio de la inversa de la elasticidad de las exportaciones. En la función de exportaciones el TCR resulta significativo. 


\section{CUADRO 2}

PRUEBA DE RAÍCES UNITARIAS. ANÁLISIS DE ESTACIONARIEDAD

\begin{tabular}{|c|c|c|c|c|c|c|}
\hline Variable & $\mathrm{ADF}$ & DW & Rezago & Intercepto & Tendencia & $\begin{array}{l}\text { Orden de } \\
\text { integración }\end{array}$ \\
\hline \multicolumn{7}{|c|}{ Nivel } \\
\hline LX & -0.27 & 2.57 & 0 & si & no & $\mathrm{I}(1)$ \\
\hline LM & -0.1 & 1.75 & 0 & si & no & $\mathrm{I}(1)$ \\
\hline LY & -0.63 & 3.31 & 0 & si & no & $\mathrm{I}(1)$ \\
\hline LYUS & -1.99 & 1.2 & 0 & si & si & $\mathrm{I}(1)$ \\
\hline LIP & -0.72 & 2.41 & 0 & si & si & $\mathrm{I}(1)$ \\
\hline LIPU & -4.71 & 2.22 & 0 & si & si & $\mathrm{I}(1)$ \\
\hline LIED & -3 & 2.6 & 0 & si & no & $\mathrm{I}(1)$ \\
\hline LIEDNR & -2 & 3.11 & 0 & no & no & $\mathrm{I}(1)$ \\
\hline LTCR & -0.88 & 1.48 & 0 & si & si & $\mathrm{I}(1)$ \\
\hline LR & -0.54 & 2.19 & 0 & si & no & $\mathrm{I}(1)$ \\
\hline \multicolumn{7}{|c|}{$1^{\mathrm{a}}$ Diferencia } \\
\hline DLX & -14.12 & 1.97 & 0 & si & no & $\mathrm{I}(0)$ \\
\hline DLM & -9.46 & 2.07 & 0 & si & no & $\mathrm{I}(0)$ \\
\hline DLY & -23.7 & 1.8 & 0 & si & no & $\mathrm{I}(0)$ \\
\hline DLYUS & -8.18 & 2.09 & 0 & si & si & $\mathrm{I}(0)$ \\
\hline DLIP & -12.92 & 1.97 & 0 & si & si & $\mathrm{I}(0)$ \\
\hline DLIPU & -11.14 & 2.01 & 0 & si & si & $\mathrm{I}(0)$ \\
\hline DLIED & -16 & 2.3 & 0 & si & no & $\mathrm{I}(0)$ \\
\hline DLIEDNR & -21.47 & 2.43 & 0 & no & no & $\mathrm{I}(0)$ \\
\hline DLTCR & -8.13 & 2.12 & 0 & si & no & $\mathrm{I}(0)$ \\
\hline
\end{tabular}

Fuente: elaboración propia.

consistente con el equilibrio externo se sitúa en 2.49 , valor bastante cercano a la senda de largo plazo mostrada por la economía mexicana en el periodo (1.96), aunque en un nivel superior, lo que sugiere que las posibilidades de crecimiento de la economía mexicana se han visto limitadas por factores adicionales. En el caso de la segunda estimación que incluye la participación de la IED y las remesas, el cociente 
de elasticidades arroja un valor de 0.73. Con ello se observa un valor alto en la elasticidad de la demanda de importaciones (5.6) que contrasta con una elasticidad baja de las exportaciones. Este aspecto es consistente con las estimaciones que se han hecho en el caso mexicano, que muestran un alza paulatina en el apetito por las compras externas y un menor efecto impulsor de las exportaciones, especialmente de las manufactureras, lo que ha redituado en un menor ritmo de crecimiento económico. Asimismo se observa que existe un papel significativo de la IED y las remesas, impactando el primero de forma negativa, mientras que las remesas han influido a relajar la presión externa aunque con un peso muy limitado (Véase Cuadro 3).

\section{CUADRO 3}

\section{ESTIMACIÓN Y PRUEBAS DE COINTEGRACIÓN DE JOHANSEN}

Coeficientes de cointegración normalizados (error estándar en paréntesis)

$$
\begin{aligned}
& \mathrm{LY}=14.09291+0.104148^{*} \mathrm{LX}-0.041427^{*} \mathrm{LTCR}+0.743446^{*} \mathrm{LYUS}+ \\
& +0.002440^{*} \mathrm{LR}-0.021491^{*} \mathrm{LIED} \\
& \begin{array}{llllll}
(2.14193) & (0.04613) & (0.01073) & (0.28603) & (0.03861) & (0.02074)
\end{array}
\end{aligned}
$$

\begin{tabular}{|c|c|c|c|c|}
\hline \multicolumn{5}{|l|}{ Test de cointegración de la traza } \\
\hline Ecuaciones de Cointegración & Eigenvalue & $\begin{array}{c}\text { Estadístico } \\
\text { de la } \\
\text { Traza }\end{array}$ & $\begin{array}{c}\text { Valor } \\
\text { Crítico } \\
0.05\end{array}$ & Prob. ${ }^{* *}$ \\
\hline Ninguno * & 0.384064 & 138.2986 & 103.8473 & 0.0000 \\
\hline Al menos $1 *$ & 0.340951 & 85.47586 & 76.97277 & 0.0097 \\
\hline \multicolumn{5}{|c|}{ Test de cointegración del máximo valor crítico } \\
\hline Ecuaciones de Cointegración & Eigenvalue & $\begin{array}{c}\text { Estadístico } \\
\text { de la } \\
\text { Traza }\end{array}$ & $\begin{array}{c}\text { Valor } \\
\text { Crítico } \\
0.05\end{array}$ & Prob. ${ }^{* *}$ \\
\hline Ninguno * & 0.384064 & 52.82271 & 40.95680 & 0.0015 \\
\hline Al menos $1 *$ & 0.340951 & 45.44842 & 34.80587 & 0.0019 \\
\hline
\end{tabular}


En todo caso la tasa de crecimiento de equilibrio que se obtiene muestra un valor muy cercano a la senda de largo plazo de la economía mexicana, incluso con una brecha menor a la diferencia observada dentro del primer modelo estimado. El Cuadro 4 muestra las estimaciones de los parámetros estimados por los vectores de cointegración con resultados interesantes porque dejan abierto el análisis a la incorporación de otros efectos en el análisis de la restricción externa, además de que invitan a profundizar el estudio sobre el impacto y las transformaciones al interior del periodo.

\section{CUADRO 4}

TASA DE CRECIMIENTO MEDIA OBSERVADA Y RESTRINGIDA POR LA BALANZA DE PAGOS

\begin{tabular}{|c|c|c|c|c|c|c|c|c|}
\hline periodo & YEEUU & YMEX & $(\varepsilon / \pi)^{1}$ & $(\varepsilon / \pi)^{2}$ & $\mathrm{yb}^{1}$ & $\mathrm{yb}^{2}$ & $\mathrm{yb}^{1}-\mathrm{yobs}$ & $\mathrm{yb}^{2}-\mathrm{yobs}$ \\
\hline $1980-2007$ & 2.40 & 1.96 & 1.04 & 0.73 & 2.49 & 1.75 & 0.53 & -0.21 \\
\hline
\end{tabular}

Fuente: elaboración propia.

\section{Balance y enseñanzas del análisis de la REC para México}

El debate de la restricción externa y el crecimiento económico está lejos de ser zanjado. La revisión de la literatura sobre el tema ha dejado ver que el papel de la demanda es fundamental en la explicación de la dinámica económica de largo plazo pero no basta por sí solo. Por tanto, es necesario acompañarlo de características que incorporen la perspectiva del lado de la oferta, a fin de obtener una fotografía completa del fenómeno de la restricción al crecimiento. La evidencia empírica correspondiente al modelo de brechas sugiere que la persistencia de los fenómenos de desequilibrio en los países de la región latinoamericana ha dejado una profunda huella en la región. La transformación estructural emprendida a partir de la década de los ochenta ha llevado a transitar por etapas de fuerte ajuste macroeconómico y liberalización, en una coyuntura de recesión en los años ochenta, así como de crisis y recu- 


\section{CUADRO A1 \\ PRINCIPALES ESTIMACIONES DE LA RESTRICCIÓN EXTERNA AL CRECIMIENTO PARA LATINOAMÉRICA}

\begin{tabular}{|c|c|c|c|c|c|c|c|c|c|c|c|c|c|c|c|c|c|c|}
\hline \multirow[t]{4}{*}{ Pais } & $\begin{array}{c}\text { Tasa de } \\
\text { crecimi } \\
\text { ento de } \\
\text { las } \\
\text { exporta } \\
\text { ciones }\end{array}$ & $\begin{array}{c}\text { Elastici } \\
\text { dad } \\
\text { ingress - } \\
\text { demand } \\
\text { a de } \\
\text { importa } \\
\text { ciones }\end{array}$ & $\begin{array}{c}\text { Tasa de } \\
\text { crecimi } \\
\text { ento de } \\
\text { equilibri } \\
\text { o en } \\
\text { Balanza } \\
\text { de } \\
\text { Pagos }\end{array}$ & $\begin{array}{c}\text { Tasa de } \\
\text { crecimi } \\
\text { ento } \\
\text { actual }\end{array}$ & $\begin{array}{c}\text { Desviac } \\
\text { ion } \\
\text { entre y / } \\
\text { ye }\end{array}$ & $\begin{array}{c}\text { Elastici } \\
\text { dad } \\
\text { ingrese- } \\
\text { demand } \\
\text { a de } \\
\text { importa } \\
\text { ciones }\end{array}$ & $\begin{array}{c}\text { Tasa de } \\
\text { crecimi } \\
\text { ento de } \\
\text { equilibri } \\
\text { o en } \\
\text { Balanza } \\
\text { de } \\
\text { Pagos }\end{array}$ & $\begin{array}{c}\text { Tasa de } \\
\text { crecimi } \\
\text { ento } \\
\text { actual }\end{array}$ & $\begin{array}{c}\text { Desviac } \\
\text { ión } \\
\text { entre y } / \\
y e\end{array}$ & $\begin{array}{l}\text { Tasa de } \\
\text { crecimi } \\
\text { ento de } \\
\text { las } \\
\text { exporta } \\
\text { ciones }\end{array}$ & $\begin{array}{l}\text { Blastici } \\
\text { dad } \\
\text { ingrese } \\
\text { demand } \\
\text { a de } \\
\text { importa } \\
\text { ciones }\end{array}$ & $\begin{array}{c}\text { Tasa de } \\
\text { crecimi } \\
\text { ento de } \\
\text { equilibri } \\
\text { o en } \\
\text { Balansa } \\
\text { de } \\
\text { Pagos }\end{array}$ & $\begin{array}{c}\text { Tasa de } \\
\text { crecimi } \\
\text { ento } \\
\text { actual }\end{array}$ & $\begin{array}{c}\text { Desviac } \\
\text { ión } \\
\text { entre } y / \\
y \in\end{array}$ & $\begin{array}{c}\text { Elastici } \\
\text { dad } \\
\text { ingreso } \\
\text { demand } \\
\text { a de } \\
\text { importa } \\
\text { ciones }\end{array}$ & $\begin{array}{c}\text { Tasa de } \\
\text { crecimi } \\
\text { ento de } \\
\text { equilibri } \\
\text { o en } \\
\text { Balanza } \\
\text { de } \\
\text { Pagos }\end{array}$ & $\begin{array}{l}\text { Tasa de } \\
\text { crecimi } \\
\text { ento } \\
\text { actual }\end{array}$ & $\begin{array}{c}\text { Desviac } \\
\text { ión } \\
\text { entre } y / \\
y e\end{array}$ \\
\hline & \multicolumn{5}{|c|}{ Pacheco-Lopez y Thirlwall (2006) } & \multicolumn{4}{|c|}{$C B P A L(2005)$} & \multicolumn{5}{|c|}{ Pernaton (2003) } & \multicolumn{4}{|c|}{ Holland, Vilela y Canuto (2004) } \\
\hline & \multicolumn{5}{|c|}{$1977-2002$} & \multicolumn{4}{|c|}{$1980-2004$} & \multicolumn{5}{|c|}{$1973-1995$} & \multicolumn{4}{|c|}{ varios años** } \\
\hline & $x$ & $\pi a$ & $\begin{array}{l}y e= \\
x / \pi\end{array}$ & $y$ & $y / y e$ & $\pi a$ & $\begin{array}{l}y e= \\
x / \pi\end{array}$ & $y$ & $y / y b$ & $x$ & $\pi a$ & $\begin{array}{l}y e= \\
x / \pi\end{array}$ & $y$ & $y / y e$ & $\pi a$ & $\begin{array}{l}y e= \\
x / \pi\end{array}$ & $y$ & $y / y e$ \\
\hline Argentina & 6.07 & $\begin{array}{l}3.66 \\
(7.58) \\
\end{array}$ & 1.66 & 1.33 & -0.33 & 3.01 & 2.11 & 1.53 & -0.58 & 1.31 & 3.01 & 1.41 & 1.16 & -0.25 & 4.07 & 2.26 & 2.12 & -0.14 \\
\hline Barbados & & & & & & 2.92 & 1.91 & 1.14 & -0.77 & & & & & & & & & \\
\hline Brazl & 8.07 & $\begin{array}{c}1.59 \\
(2.25) \\
\end{array}$ & 5.08 & 2.70 & -2.38 & 3.26 & 2.29 & 2.16 & -0.13 & 1.92 & 1.77 & 3.53 & 2.94 & -0.59 & 2.16 & 3.42 & 5.34 & 1.92 \\
\hline Chile & 8.62 & \begin{tabular}{c|}
2.03 \\
$(6.17)$ \\
\end{tabular} & 4.24 & 5.50 & 1.26 & 1.48 & 4.79 & 4.58 & -0.21 & & & & & & 2.71 & 3.33 & 3.90 & 0.57 \\
\hline Colombia & & & & & & 1.94 & 3.21 & 3.17 & -0.04 & & & & & & 4.35 & 2.26 & 3.94 & 1.68 \\
\hline Costa Rica & 7.38 & \begin{tabular}{c|}
2.27 \\
$(6.34)$ \\
\end{tabular} & 3.25 & 3.94 & 0.69 & 2.17 & 4.21 & 3.74 & -0.47 & 2.77 & 1.76 & 5.12 & 3.32 & -1.80 & 0.42 & 2.52 & 4.14 & 1.62 \\
\hline Cuba & & & & & & & & & & & & & & & & & & \\
\hline Dominica & & & & & & 2.07 & 3.26 & 2.50 & -0.76 & & & & & & & & & \\
\hline Ecuador & 5.38 & $\begin{array}{c}1.83 \\
(2.62) \\
\end{array}$ & 2.94 & 2.57 & -0.37 & 3.93 & 1.06 & 2.48 & 1.42 & 0.61 & 0.24 & 8.26 & 3.31 & -4.95 & & & & \\
\hline El Salvador & 5.03 & $\begin{array}{c}2.47 \\
(6.68) \\
\end{array}$ & 2.04 & 1.66 & -0.38 & 2.32 & 2.26 & 2.05 & -0.21 & & & & & & & & & \\
\hline Granada & & & & & & 1.19 & 4.34 & 3.68 & -0.66 & & & & & & & & & \\
\hline Guatemala & 2.14 & $\begin{array}{l}3.78 \\
(3.60) \\
\end{array}$ & 0.57 & 2.93 & 2.36 & 2.43 & 2.92 & 2.47 & -0.45 & & & & & & & & & \\
\hline Jamaica & & & & & & 0.81 & 2.91 & 1.59 & -1.32 & 0.55 & 1.51 & 1.18 & 0.65 & -0.53 & & & & \\
\hline México & 11.38 & $\begin{array}{c}3.17 \\
(5.40) \\
\end{array}$ & 3.59 & 3.30 & -0.29 & n.d & n.d & n.d & nd & & & & & & 4.58 & 2.72 & 4.62 & 1.90 \\
\hline Nicaragua & 1.40 & $\begin{array}{c}0.97 \\
(1.59)^{*}\end{array}$ & 1.44 & 0.45 & -0.99 & n.d & n.d & nd & nd & & & & & & & & & \\
\hline Panamá & & & & & & nd & n.d & nd & nd & 1.21 & 0.26 & 15.13 & 3.06 & -12.07 & & & & \\
\hline Paraguay & 7.01 & $\begin{array}{c}2.48 \\
(2.53) \\
\end{array}$ & 2.83 & 3.73 & 0.90 & 3.87 & 2.56 & 2.51 & -0.05 & & & & & & & & & \\
\hline Perú & 5.25 & $\begin{array}{c}1.56 \\
(4.85) \\
\end{array}$ & 3.37 & 1.93 & -1.44 & 320 & 1.45 & 1.91 & 0.46 & 0.69 & 0.94 & 2.39 & 0.99 & -1.40 & 2.53 & 2.84 & 3.52 & 0.68 \\
\hline $\begin{array}{c}\text { Rep. } \\
\text { Dominicana }\end{array}$ & 7.84 & $\begin{array}{c}0.92 \\
(0.76)^{*}\end{array}$ & 8.52 & 4.23 & -4.29 & 1.89 & 5.50 & 3.89 & -1.61 & 1.91 & 1.15 & 5.40 & 3.32 & -2.08 & & & & \\
\hline $\begin{array}{c}\text { San Cristobal } \\
\text { y Nevis }\end{array}$ & & & & & & 1.72 & 4.44 & 4.58 & 0.14 & & & & & & & & & \\
\hline Saint Lucia & & & & & & 1.22 & 4.42 & 3.72 & -0.70 & & & & & & & & & \\
\hline $\begin{array}{c}\text { San Vicente y } \\
\text { Granadinas }\end{array}$ & & & & & & 1.95 & 2.81 & 4.47 & 1.66 & & & & & & & & & \\
\hline $\begin{array}{c}\text { Trimidad y } \\
\text { Tobago }\end{array}$ & & & & & & & & & & 1.78 & 1.43 & 4.05 & 0.62 & -3.43 & & & & \\
\hline Uruguay & 4.05 & $\begin{array}{c}2.13 \\
(6.27) \\
\end{array}$ & 1.90 & 1.43 & -0.47 & 1.35 & 2.99 & 1.53 & -1.46 & 1.49 & 2.78 & 1.74 & 1.61 & -0.13 & 3.48 & 1.61 & 1.77 & 0.16 \\
\hline Venezuela & 1.74 & \begin{tabular}{|c|}
3.76 \\
$(4.59)$ \\
\end{tabular} & 0.46 & 1.13 & 0.67 & 1.37 & 2.30 & 1.32 & -0.98 & & & & & & 3.83 & 1.54 & 3.29 & 1.75 \\
\hline
\end{tabular}

Notas: El asterisco indica que $\pi$ no es estadísticamente significativa al 95 por ciento de nivel de confianza.

Desviación estándar en paréntesis.

n.d: no disponible.

** Argentina (1969-2000), Bolivia (1969-2000), Brasil (1951-2000), Chile (1961-2000), Colombia (1969-2000), Ecuador (1966-2000), México (1958-1999), Perú (1951-2000), Uruguay (1956-2000), Venezuela (1958-2000). 


\section{CUADRO A1 (continuación)}

\section{PRINCIPALES ESTIMACIONES DE LA RESTRICCIÓN EXTERNA AL CRECIMIENTO PARA LATINOAMÉRICA}

\begin{tabular}{|c|c|c|c|c|c|c|c|c|c|c|c|c|c|c|c|c|c|}
\hline $\begin{array}{l}\text { Tasa de } \\
\text { crecimi } \\
\text { ento de } \\
\text { las } \\
\text { exporta } \\
\text { ciones }\end{array}$ & $\begin{array}{c}\text { Elastici } \\
\text { dad } \\
\text { ingreso- } \\
\text { demand } \\
\text { a de } \\
\text { importa } \\
\text { ciones }\end{array}$ & $\begin{array}{l}\text { Tasa de } \\
\text { crecimi } \\
\text { ento de } \\
\text { equilibri } \\
\text { oen } \\
\text { Balanza } \\
\text { de } \\
\text { Pagos }\end{array}$ & $\begin{array}{c}\text { Tasa de } \\
\text { crecimi } \\
\text { ento } \\
\text { actual }\end{array}$ & $\begin{array}{c}\text { Desviac } \\
\text { ion } \\
\text { entre y/ } \\
\text { ye }\end{array}$ & $\begin{array}{c}\text { Elastici } \\
\text { dad } \\
\text { ingreso- } \\
\text { demand } \\
\text { a de } \\
\text { importa } \\
\text { ciones } \\
\text { (pre- } \\
\text { ref orma } \\
\text { ) }\end{array}$ & $\begin{array}{c}\text { Blastici } \\
\text { dad } \\
\text { ingreso- } \\
\text { demand } \\
\text { a de } \\
\text { importa } \\
\text { ciones } \\
\text { (post- } \\
\text { ref orma } \\
\text {, }\end{array}$ & $\begin{array}{c}\text { Tasa de } \\
\text { crecimi } \\
\text { onto de } \\
\text { equilibri } \\
\text { oen } \\
\text { Balanza } \\
\text { de } \\
\text { Pagos } \\
\text { (past) }\end{array}$ & $\begin{array}{c}\text { Tasa de } \\
\text { crecimi } \\
\text { ento } \\
\text { actual } \\
\text { (past) }\end{array}$ & $\begin{array}{c}\text { Desviac } \\
\text { ion } \\
\text { entre y/ } \\
\text { ye }\end{array}$ & $\begin{array}{c}\text { Blastici } \\
\text { dad } \\
\text { ingreso- } \\
\text { demand } \\
\text { a de } \\
\text { importa } \\
\text { ciones }\end{array}$ & $\begin{array}{l}\text { Tasa de } \\
\text { crecimi } \\
\text { ento de } \\
\text { equilibri } \\
\text { o en } \\
\text { Balanca } \\
\text { de } \\
\text { Pagas }\end{array}$ & $\begin{array}{c}\text { Tasa de } \\
\text { crecimi } \\
\text { ento } \\
\text { actual }\end{array}$ & \begin{tabular}{|c|} 
Desviac \\
ion \\
entre $y /$ \\
$y e$
\end{tabular} & $\begin{array}{l}\text { Tasa de } \\
\text { erecimi } \\
\text { ento de } \\
\text { las } \\
\text { exporta } \\
\text { ciones }\end{array}$ & $\begin{array}{c}\text { Blastici } \\
\text { dad } \\
\text { ingreso } \\
\text { demand } \\
\text { a de } \\
\text { importa } \\
\text { ciones }\end{array}$ & $\begin{array}{l}\text { Tasa de } \\
\text { crecimi } \\
\text { ento de } \\
\text { equilibri } \\
\text { oen } \\
\text { Balansa } \\
\text { de } \\
\text { Pagos }\end{array}$ & $\begin{array}{l}\text { Tasa de } \\
\text { crecimi } \\
\text { ento } \\
\text { actual }\end{array}$ \\
\hline \multicolumn{5}{|c|}{ Perraton (2003) [deudores] } & \multicolumn{5}{|c|}{ Cimollity Correa (2002) aa } & \multicolumn{4}{|c|}{ Moreno-Brid y Pérez (1999) } & \multicolumn{4}{|c|}{ Thirboally Hussein (1982) } \\
\hline \multicolumn{5}{|c|}{$1973-1995$} & \multicolumn{5}{|c|}{ * varios años } & \multicolumn{4}{|c|}{$1950-1994^{a}(1996)$} & \multicolumn{4}{|c|}{$1951-1960(1969)$} \\
\hline$x$ & $\pi a$ & $\begin{array}{l}y e= \\
x / \pi\end{array}$ & $y$ & $y / y e$ & $\pi a$ & $\pi a$ & $\begin{array}{l}y e= \\
x / \pi\end{array}$ & $y$ & $y / y e$ & $\pi a$ & $\begin{array}{c}y e= \\
x / \pi\end{array}$ & $y$ & $y / y e$ & $x$ & $\pi a$ & $\begin{array}{l}y e= \\
x / \pi\end{array}$ & $y$. \\
\hline 1.31 & 3.01 & 1.54 & 1.84 & 0.30 & -0.07 & 3.97 & 2.69 & 3.95 & 1.26 & & & & & & & & \\
\hline & & & & & & & & & & & & & & & & & \\
\hline 0.23 & 0.50 & 1.62 & 3.21 & 1.59 & & & & & & & & & & & & & \\
\hline 1.92 & 1.77 & 3.83 & 5.71 & 1.88 & 0.59 & 6.42 & 1.28 & 2.42 & 1.14 & & & & & $0.08^{a}$ & $2.05^{\mathrm{a}}$ & $0.094^{x}$ & $0.09^{n}$ \\
\hline & & & & & 0.65 & 1.98 & 4.21 & 6.75 & 2.54 & & & & & & & & \\
\hline & & & & & 0.68 & 5.47 & 0.78 & 2.50 & 1.72 & & & & & 0.03 & 0.29 & 0.06 & 0.05 \\
\hline & & & & & & & & & & 1.10 & 5.30 & 4.70 & -0.60 & 0.08 & 2.04 & 0.05 & 0.04 \\
\hline & & & & & & & & & & & & & & & & & \\
\hline & & & & & & & & & & & & & & & & & \\
\hline 0.61 & 0.24 & 8.97 & 6.28 & -2.69 & & & & & & & & & & 0.06 & 0.56 & 0.11 & 0.05 \\
\hline & & & & & & & & & & 1.75 & 3.40 & 1.90 & -1.50 & & & & \\
\hline & & & & & & & & & & & & & & & & & \\
\hline & & & & & & & & & & 1.35 & 3.80 & 3.30 & -0.50 & & & & \\
\hline & & & & & & & & & & & & & & & & & \\
\hline & & & & & & & & & & $3.7^{\star}$ & $3.8^{n}$ & $0.7^{*}$ & -3.10 & $0.7^{\star}$ & $0.89^{x}$ & $0.082^{2}$ & $0.04^{x}$ \\
\hline & & & & & & & & & & & & & & $0.52^{a}$ & $0.70^{2}$ & $0.058^{\mathrm{a}}$ & $0.04^{x}$ \\
\hline & & & & & 0.82 & 4.28 & 2.06 & 3.16 & 1.10 & & & & & $0.06^{a}$ & $0.05^{\mathrm{a}}$ & 0.10 & $0.06^{\mathrm{a}}$ \\
\hline & & & & & & & & & & 2.04 & 2.60 & 2.10 & -0.50 & & & & \\
\hline 1.21 & 0.26 & 16.43 & 5.02 & -11.41 & & & & & & & & & & & & & \\
\hline 0.69 & 0.94 & 2.59 & 2.84 & 0.25 & 0.82 & 4.28 & 2.81 & 5.08 & 2.27 & & & & & & & & \\
\hline & & & & & & & & & & & & & & & & & \\
\hline & & & & & & & & & & & & & & & & & \\
\hline & & & & & & & & & & & & & & & & & \\
\hline & & & & & & & & & & & & & & & & & \\
\hline 1.78 & 1.43 & 4.39 & 6.89 & 2.50 & & & & & & & & & & & & & \\
\hline 1.49 & 2.78 & 1.89 & 4.27 & 2.38 & -0.42 & 2.92 & 0.45 & 2.06 & 1.61 & & & & & & & & \\
\hline & & & & & & & & & & & & & & & & & \\
\hline
\end{tabular}

aa [Países en periodo pre-reforma y post-reforma] Argentina pre: (1970-1990) (1991-1999); Brasil (1970-1989) (1990-1999) Chile (1970-1984) (1995-1998) Colombia (1970-1989) (1989-1990) México (1970-1985) (19861999) Perú (1970-1989) (1996) Uruguay (1970-1977) (1978-1999).

Fuente: elaboración propia con datos de Pacheco-López y Thirlwall (2006), CEPAL (2005), Perraton (2003), Holland, Vilela y Canuto (2004), Moreno-Brid y Pérez. (1999). 
peración a partir de los años noventa -principalmente a causa de impulsos externos. Este marco, si bien configuró una nueva realidad económica, acentuó los problemas estructurales de las economías y con ello las restricciones al crecimiento se hicieron más evidentes. El caso mexicano es contrastante. Es una de las economías latinoamericanas con mayor avance en materia de reformas estructurales. No obstante, su dinámica de crecimiento es más volátil y menor que el promedio regional, situándola actualmente en una trampa de crecimiento lento. En este sentido, los estudios realizados desde la perspectiva del modelo REC, así como su modelo ampliado, si bien reconocen estas características, todavía sigue siendo de forma parcial. Parece haber una contradicción, ya que la mayoría de los análisis del caso mexicano se han limitado a confirmar la conveniencia del modelo de Thirlwall en la explicación de la tasa de crecimiento de largo plazo en un contexto en el que la realidad empírica y el avance teórico aconsejan ampliar las posibilidades de análisis. En este sentido, las enseñanzas más recientes sugieren incorporar otros elementos inherentes al proceso de industrialización como son las características de oferta en las funciones de comercio, así como reconsiderar las particularidades nacionales.

\section{Bibliografía}

[1] AGHION, P. y P. HOWITT (1998): Endogenous Growth Theory, Massachusetts Institute of Technology. Cambridge, MA.

[2] AGÉNOR, P.R (2004): The economics of adjustment and growth, Academic Press. $2^{\mathrm{a}}$ edición, EEUU.

[3] ALONSO, J.A y GARCIMARTÍN, C. (1999): "On Convergence and Balance of Payments Constraint", International Journal of Development Planning Literature, vol 14, $\mathrm{N}^{\circ}$ 4. Octubre-Diciembre, pp. 483-497.

[4] ALONSO, J.A. y C. GARCIMARTÍN (1998): "A New Approach to Balance-ofPayments Constraint, Some Empirical Evidence". Journal of Post-Keynesian Economics. Vol. 21, n. ${ }^{\circ}$ 2, Winter, pp. 259-82

[5] ALONSO, J.A. y C. GARCIMARTÍN (1998): "La restricción externa al crecimiento: nuevos enfoques". Revista de Economía Aplicada. Número 16 (vol. VI), pp. 5-37.

[6] ALONSO, J.A (1996): "Demanda, exportaciones y crecimiento: el caso español”. Pensamiento Iberoamericano. Revista de economía política, Madrid.

[7] ALONSO, J.A (1999): "Growth and the external constraint: lessons from the Spanish case". Applied Economics, 31, pp. 245-253.

[8] ANSARI, HASHEMZA \& XI (2000): "The chronicle of economic growth in Southeast Asian countries: does Thirlwall's law provide an adequate explanation? Journal of Post keynesian Economics. Summer, vol 22, No 4, pp. 573-588.

[9] ARAUJO. R. y G. LIMA (2007): "A structural economic dynamics approach to balanceof-payments constrained growth". Cambridge Journal of Economics, pp. 1-20.

[10] AREVILCA, B. y A. RISSO (2007): "El modelo de crecimiento restringido por balanza de pagos. Evidencia empírica para Bolivia, 1953-2002”, Revista Venezolana de Análisis de Coyuntura, enero-junio, $\mathrm{N}^{\mathrm{o}}$ 001, pp. 203-231. 
[11] ASPE, P. (1993): The Economic Transformation: The Mexican way. MIT Press. Cambridge MA.

[12] BACHA, E. (1982): "Crescimento com oferta limitada de divisas: uma reavaliação do modelo de dois hiatos", Pesquisa e Planejamento Econômico, 12(2), agosto, pp. 285-310.

[13] BACHA, E. (1990): "A three-gap model of foreign transfers and the GDP growth rate in developing countries". Journal of Development Economics. Vol. 32, 2, abril, pp. 279-296.

[14] BAIRAM, E. (1988): "Balance of payments, the Harrod foreign trade multiplier; and economic growth: The European and North American experience, 1970-1985'. Applied Economics, 20, diciembre, pp. 1635-1642.

[15] BANCO DE MÉXICO. Estadisticas. Version on line, en: http://www.banxico.org.mx/tipo/estadisticas/index.html

[16] BANCO MUNDIAL (2009): World Development Indicators 2009, Washington DC, version on-line.

[17] BARBOSA-FILHO, N. RADA, C. TAYLOR y L. ZAMPARELLI (2006): "Fiscal, Foreign, And Private Net Borrowing: Widely Accepted Theories Don'T Closely Fit The Facts". ANPEC Anais do XXXIV Encontro Nacional de Economia [Proceedings of the 34th Brazilian Economics Meeting] No 177.

[18] BELLOC y VERTOVA (2004): "How Does Public Investment Affect Economic Growth in HIPC? An Empirical Assessment". Dipartamento di Economia Politica, $N^{o}$ 416. Università degli Studi di Siena.

[19] BLECKER, R. (1998): "International competitiveness, relative wages, and the balanceof-payments constraints”. Journal of Post Keynesian Economics; Summer, 20, 4, pp. 495-526.

[20] BOYER, R. y P. PETIT (1989): "The cumulative growth model revisited", Political. Economy, Vol. 4, Núm. 1, pp. 23-43.

[21] BRITTO, G (2008): “Thirlwall's Law and the Long-Term Equilibrium Growth Rate: an Application for Brazil (1951-2006)". Cambridge Centre for Economic and Public Policy, CCEPP WP01-08, junio.

[22] CARNEIRO, D. y R. WERNECK, (1989), "Brazil growth exercises for the nineties", mimeo, Departamento de Economía PUC-RJ Agosto.

[23] CIMOLLI, N. y C. CORREA (2002): "Trade Openness and Technological Gaps in Latin America: A 'Low Growth Trap" Laboratory of Economics and Management Working paper. CEPAL. 2002/14.

[24] CEPAL (2005): "Long term growth in the Caribbean. A balance of payments constraints approach". Limited. LC/CAR/L.63. 14 Deciembre, disponible en: http://www.eclac.org/publicaciones/xml/2/23232/L.63.pdf

[25] CHENERY, H.B. y BRUNO (1962): "Development alternatives in an open economy: the case of Israel”, The Economic Journal, Vol. 72, No. 285 (Mar., 1962), pp. 79-103.

[26] CHENERY, H.B. y A.M. STROUT (1966): "Foreign assistance and economic development", The American Economic Review, vol. LVI, n 4, p. 679-733.

[27] CHENERY, H. y CARTER (1966): "Internal and external aspects of development plans and performance, 1960-1970”. Development Policy Staff Working Paper Nº 11. International Bank for Reconstruction and Development, febrero. 
[28] CORDOBA, J. (1993): “The political economy of policy reform". Institute for International Economics. USA.

[29] DOMINIONI, D. y J. LICANDRO (1990): "Una aplicación del modelo de dos brechas al caso de Uruguay", UNIRED, Uruguay.

[30] DUTT, A.K. (2002): “Thirlwall's Law and uneven development”. Journal of Post Keynesian Economics, Spring 2002, Vol. 24, No. 3, pp. 367-390.

[31] DUTT A.K, y J. ROS (eds.) (1993): Development Economics and Structuralist Macroeconomics. Essays in Honor of lance Taylor. Edward Elgar Publishing Limited. UK, pp. 450.

[32] FANELLI, J.M. y R. FRENKEL (1989): “Growth exercise for Argentina”, Documento CEDES $\mathrm{N}^{\circ} 25$, Buenos Aires.

[33] FITZGERALD, V. (2007): "Fiscal Strategy and Social Contract in Latin America”, paper presentado al SEGIB/IDB workshop Modern Markets and Traditional Politics Junio 4-5, 2007 en el Latin American Centre, University of Oxford.

[34] FITZGERALD, V. (1999): "Trade, Investment and NAFTA: The economics of neighbourhood" en Bulmer-Thomas and Durkeley J. (eds). The United States and Latin America: The New Agenda. University of London and Harvard University.

[35] FRENCH-DAVIS, R. (2005): Reformas para América Latina después del Fundamentalismo Neoliberal, CEPAL y Siglo XXI Editores. Argentina

[36] FUGAROLAS, G. y D. MATESANZ (2005): "Restricción de balanza de pagos y vulnerabilidad externa en la argentina de los noventa. Un análisis de caso". Munich Personal RePEc Archive. MPRA Paper, No. 210, disponible en: http:// mpra.ub.uni-muenchen.de/ 210/

[37] GARCÍA, M. y A. QUEVEDO (2005): “Crecimiento económico y balanza de pagos: evidencia empírica para Colombia”, Cuadernos de Economía, v. XXIV, n. 43, Bogotá, pp. 83-104.

[38] GARCÍA MOLINA, M. y J.K. RUIZ TAVERA (2008): “Ley De Thirlwall Y Modelo De Brechas: Un Modelo Unificado”. Documento de trabajo. Escuela de Economía. Universidad de Colombia.

[39] GARCIMARTIN, C. (2008): "Crecimiento económico desde un enfoque de demanda". Principios, Estudios de Economía Política, 8, pp. 85-94.

[40] GONZAGA, F. (2003): "Balance-of-Payments-Constrained Economic Growth in Brazil". Brazilian Journal of Political Economy, vol. 23, n 1 (89), enero-marzo, pp. 62-84.

[41] GUERRERO DE L., G. (2007): "Determinantes del Crecimiento. El caso de México. 1986-2003”. Revista de Desarrollo, vol 38, No 148 enero-marzo, pp. 153-171.

[42] HARROD (1933): International Economics, Cambridge University Press, Cambridge.

[43] HAUSMANN, R., L. PRITCHETT y D. RODRIK (2005): “Growth Accelerations". Journal of Economic Growth. Volume 10, Number 4 / diciembre, pp. 303-329.

[44] HELPMAN, E., O. ITSKHOKI y S. REDDING (2008): "Inequality and unemployment in a global economy". NBER Working Paper No. w14478. Noviembre.

[45] HOLLAND, M. F. VILELA y O. CANUTO (2004): "Economic Growth and the Balance of Payments Constraint in Latin America". Investigación Económica, vol. LXIII 247, enero-marzo, pp. 45-74. 
[46] HUSSEIN, M. (2006): “The implications of Thirlwall's law for Africa's development challenges" en Arestis, P., McCombie, J.S.L., Vickerman, R. \& Thirlwall, A.P. Growth and economic development: essays in honour of A.P. Thirlwall. Edward Elgar Publishing, 2004, pp. 21-47.

[47] HUSSEIN, N. (1999): "The Balance of Payments Constraint and Growth Rate Differences among African and East Asian Economies". African Development Bank. Blackwell Publishers, pp. 103-137.

[48] KALDOR, N. (1957): “A Model of Economic Growth”. The Economic Journal, Vol. $67, N^{\circ} .268$, pp. 591-624.

[49] KALDOR, N. (1966): Causes of the Slow Rate of Economic Growth of the United Kingdom. Cambridge University Press, Cambridge.

[50] KALDOR, N. (1996): Causes of growth and stagnation in the world economy. Cambridge University Press.

[51] KEYNES, J.M. (1930): Tratado del dinero. Teoría pura y aplicada de dinero. Ed. Acosta. España.

[52] LOPEZ, J. \& A. CRUZ (2000): “Thirlwall's law and beyond Latin American experience". Journal of Post keynesian Economics. Spring, vol. 22, No 3, pp. 477-495.

[53] LORA, E. (1992): "Ahorro, Inversión y Perspectivas de Crecimiento en Colombia", Fedesarrollo, Banco Interamericano de Desarrollo.

[54] LORÍA, E. y G. FUJI (1997): “The Balance of Payments Constraint to Mexico's Economic Growth 1950-1996”. Canadian Journal of Development Studies, Vol. 18, N. 1 pp. 119-137.

[55] LORÍA, E. (2003): “The Mexican economy: balance-of-payments -constrained growth model- the importance of the exchange rate, 1970-1999”, Journal of Post Keynesian Economics / Summer 2003, Vol. 25, No. 4.

[56] MATESANZ, D., G. FUGAROLAS y E. CANDAUDAP (2002): "Balance of Payments and Economic Growth Constrained. A Comparation between Argentine and Mexico". Revista de Economía Mundial, 17, pp. 25-49.

[57] MCCOMBIE, J. (2006): "The nature of economic growth and the neoclassical approach: more questions than answers?" en Arestis, P., McCombie, J. S. L, Vickerman, R. (eds): Growth and economic development : essays in honour of A.P. Thirlwall, Edward Elgar, UK.

[58] MCCOMBIE, J. y A. THIRLWALL (1994): Economic growth and the balance-ofpayments constraint, Mcmillan. Londres.

[59] MCGREGOR, P. y J. SWALES (1985): "Professor Thirlwall and Balance of Payments Constrained Growth". Applied Economics. Vol. 17: 1, pp. 17-32.

[60] MCGREGOR, P. y J. SWALES (1986): "Balance of Payments Constrained Growth: A Rejoinder". Applied Economics. Vol. 18: 12, pp. 1265-74.

[61] MCGREGOR, P. y J. SWALES (1991): "Thirlwall's Law and Balance of Payments Constrained Growth: Further Comment on the Debate". Applied Economics. Vol. 23: 1, pp. 9-20.

[62] MCKINNON, R. (1964): "Foreign exchange constraints in economic development and efficient aid allocation". The Economic Journal. Vol 74. No 294, junio. pp. 388-409.

[63] MORENO-BRID, J.C. (1998): "Balance of Payments Constrained Economic Growth: the Case of Mexico”, Banca Nazionale del Lavoro Quarterly Review, Vol. 207, pp. 413 433. 
[64] MORENO-BRID, J.C. (1999): "Mexico's Economic Growth and the Balance of Payments Constraint: a cointegration analysis", International Review of Applied Economics, vol. 13, $\mathrm{N}^{\mathrm{o}} 2$.

[65] MORENO-BRID, J.C. (2003): "Capital Flows, Interest Payments and the Balanceof-Payments Constrained Growth Model: A Theoretical and Empirical Analysis", Metroeconomica, Vol. 54, pp. 346-365.

[66] MORENO-BRID, J.C \& E. PÉREZ (1999): "Balance-of-payments-constraintedgrowth in Central America: 1950-1996". Journal of Post keynesian Economics. Fall, vol 22, $\mathrm{N}^{\mathrm{o}} 1$, pp. 131-147.

[67] MORENO-BRID, J.C, P.C. NÁPOLES y J.C. VALDIVIA (2004): "NAFTA and the Mexican Economy: A Look Back on a Ten-Year Relationship”. North Carolina Journal of International Law and Commercial Regulation, 2004 30: 997.

[68] NELL, K. (2004): "Explaining Long-Run Growth in South Africa and OECD Countries: Implications for the Rest of SADC Countries" en Thirlwall, A.P y McCombie J.S.L Essays on Balance of Payments Constrained Growth: Theory and Evidence. Routledge (2004), UK.

[69] OCEGUEDA HERNÁNDEZ, J.M. (2000): "La hipótesis de crecimiento restringido por la balanza de pagos. Una evaluación de la economía mexicana, 1960-1997”, Investigación Económica, vol. LX, №. 232, I-III, pp. 77-110.

[70] OCEGUEDA HERNÁNDEZ, J.M. (2003): "El sector manufacturero y la restricción externa al crecimiento económico de México”, Revista de Desarrollo, vol. 34, N 132 , abril-junio.

[71] PARIKH, A, y A. STIRBU (2004): "Relationship between Trade Liberalisation, Economic Growth and Trade Balance: An Econometric Investigation". HWWA discussion paper, $\mathrm{N}^{\mathrm{o}} 282$, Hamburg Institute of International Economics.

[72] PERRATON, J. (2003): "Balance of Payments Constrained Growth and Developing Countries: an examination of Thirlwall's hypothesis". International Review of Applied Economics, Vol. 17, № 1, pp. 1-22.

[73] PERROTINI, I. (2003): "La ley de A.P. Thirlwall: Teoría, crítica y evidencia empírica" (Introducción), en Thirlwall, A. La naturaleza del crecimiento económico. Un marco alternativo para comprender el desempeño de las naciones. FCE. México.

[74] PREBISCH, R. (1959): "Commercial Policy in the Underdeveloped Countries". The American Economic Review, Vol. 49, No. 2, Papers and Proceedings of the Seventyfirst Annual Meeting of the American Economic Association, pp. 251-273.

[75] REIG, N. y J. PARDO (2002): “Crecimiento, Demanda y Exportaciones en la Economía Uruguaya. 1960-2000”. Documentos de trabajo, No 12, Facultad de Economía. Universidad de la República, diciembre. Uruguay.

[76] RODRIGUEZ, A. (2005): "El papel de la apertura comercial en el crecimiento económico y la balanza comercial de México, 1982-2002”, Revista ICE, marzo-abril. N 821. México.

[77] ROMAGUERA, P. y D. CONTRERAS (1992): "Restricciones al crecimiento: aplicación de un modelo de brechas a fa economía chilena”, Colección de Estudios CIEPLAN $\mathrm{N}^{\circ} 36$ diciembre, pp. 145-182.

[78] ROMER, P. (1994): “The origins of endogenous growth". The Journal of Economic Perspectives. Volume 8, Number 1- Winter, pp. 3-22. 
[79] ROZENWURCEL, G. y A. VISINTINI (1990): "Proyecciones de crecimiento para la economía argentina: una aplicación del modelo de tres brechas", CEDES, Buenos Aires, agosto.

[80] SCHUMPETER, J.A. (1934): The Theory of Economic Development: An inquiry into profits, capital, credit, interest and the Business Cycle. Cambridge, Mass: Harvard University Press. $10^{a}$ Edición 2004. USA.

[81] SENHADJI, A. (1998): "Time-series estimation of structural import demand equations: a cross-country analysis", IMF Staff Papers, 45, pp. 236-68.

[82] SOLIMANO, A. (1990): "Macroeconomics constraints for medium term growth: a model for Chile", Working Paper World Bank, abril.

[83] SOLOW, R. (1956): "A Contribution to the Theory of Economic Growth", Quarterly Journal of Economics, 70, pp. 65-94.

[84] SOLOW, R. (2000): "A Toward a macroeconomics of the medium run", The Journal of Economic Perspectives-Volume 14, Number 1-Winter 2000, pp. 151-158.

[85] SUZUKI, Y. (2008): "Binding Constraint of Economic Growth Under ExportOriented Industrialization and Globalization". Seton Hall University. John C. Whitehead School of Diplomacy and International Relations. Disponible en SSRN: http://ssrn.com/abstract=1305367

[86] TAYLOR, L. (1989): "Gap disequilibria: Inflation, Investment, Savings and Foreign Exchange”, WIDER Working Paper $\mathrm{N}^{\circ} 76$, octubre.

[87] TAYLOR, L. (1991): "Foreign resource flows and developing country growth". World Institute for Development Economics Research of the United Nations University. (Helsinki, Finland).

[88] TAYLOR, L. (1994): “Gap Models”. Journal of Development Economics, Vol. 45 (1994), pp. 17-34.

[89] TAYLOR, L. (1996): “Crecimiento económico, intervención del estado y teoría del desarrollo". Pensamiento iberoamericano. Revista de economía política, Madrid, 29, pp. 31-83.

[90] TEZANOS, S., R. MADRUEÑO y M. GUIJARRO (2009): "Impacto de la ayuda sobre el crecimiento económico. El caso de América Latina y El Caribe”. Mimeo. COIBA. Universidad de Cantabria.

[91] THIRLWALL, A.P. (1979): “The Balance of Payments Constraint as an Explanation of International Growth Rate Differences". Banca Nazionale del Lavoro. Quarterly Review, vol. 32, $\mathrm{n}^{\circ} .128$.

[92] THIRLWALL, A.P. \& M.N. HUSSAIN (1982): “The Balance of Payments Constraint, capital flows and growth rate difference between developing countries". Oxford Economic Papers, 10, pp. 458-509.

[93] THIRLWALL, A.P. (1997): "Reflections on the Concept of Balance-of-PaymentsConstrained Growth". Journal of Post Keynesian Economics, núm. 3, pp. 377-85.

[94] THIRLWALL, A.P y J.S.L. MCCOMBIE (2004): Essays on Balance of Payments Constrained Growth: Theory and Evidence. Routledge. Reino Unido.

[95] THIRLWALL, A.P. (2003): La naturaleza del crecimiento económico. Un marco alternativo para comprender el desempeño de las naciones. FCE. México.

[96] THIRLWALL, A.P. y P. PACHECO-LÓPEZ (2004): “Trade Liberalisation in Mexico: Rhetoric and Reality". Banca Nazionale del Lavoro Quarterly Review. 
[97] THIRLWALL, A.P. y P. PACHECO-LÓPEZ (2006): “Trade Liberalisation, the Income Elasticity of Demand for Imports and Growth in Latin America”. Journal of Post Keynesian Economics, 29 (1). pp. 41-66.

[98] URQUIDI, V. (2005): Otro Siglo Perdido. Las políticas de desarrollo en América Latina (1930-2005), Fondo de Cultura Económica. México.

[99] VANDENBER, H. (1997): "The Relationship Between International Trade and Economic Growth in Mexico". North American Journal of Economics and Finance 8(1), pp. 1-2 I.

[100] VELASCO, R. (2006): “¿Hay restricción externa del crecimiento en Colombia de 1925 a 2000?", Cuadernos de Economía, v. XXV, n. 44, Bogotá, pp. 99-118.

[101] VELASTEGUI, L. (2007): “Crecimiento económico en el ecuador y restricciones en la balanza de pagos: una aplicación a la ley de Thirlwall. 1970-2004”. Serie de Análisis Económico, 4. Ecuador.

[102] VIDAL, P. y A. FUNDORA (2008): "Relación comercio crecimiento en Cuba: estimación con el filtro de Kalman". Revista de la CEPAL, 94, abril, pp. 101-120.

[103] VILLAR, L. y J.A. OCAMPO (1990): "Colombia: médium run growth prospecls: a simple three gap model”, mimeo FEDESARROLLO.

[104] VILLARREAL, R. (2005), Industrialización, competitividad y desequilibrio externo en México. Un enfoque macroindustrial y financiero (1929-2010). $5^{\mathrm{a}}$ edición. Fondo de Cultura Económica. México.

[105] YOUNG, A (1928): "Increasing returns and economic progress". The Economic Journal, December.

[106] YONGBOK, J. (2009): "Balance-of-payment constrained growth: the case of China, 1979-2002”. International Review of Applied Economics, Volumen 23, Issue 2. Marzo, pp. 135-146. 


\section{ANEXO 1}

Estadísticos del procedimiento de Johansen para el modelo ampliado:

\section{CUADRO A}

FUENTES DE INFORMACIÓN (EPÍGRAFE 4)

\begin{tabular}{|l|l|l|}
\hline Variable & \multicolumn{1}{|c|}{ Definición } & \multicolumn{1}{|c|}{ Fuente } \\
\hline LX & $\begin{array}{l}\text { Logaritmo de las exportaciones totales de México. } \\
\text { Exportación de mercancías (incluye maquiladoras) } \\
\text { millones de dólares base 1980 }\end{array}$ & Banco de México \\
\hline LM & $\begin{array}{l}\text { Logaritmo de las importaciones totales de México. } \\
\text { Importación de mercancías (incluye maquiladoras) } \\
\text { millones de dólares base 1980 }\end{array}$ & Banco de México \\
\hline LTCR & $\begin{array}{l}\text { Logaritmo del tipo de cambio real. Tipo de cambio } \\
\text { real base 1990 }\end{array}$ & Banco de México \\
\hline LYUS0 & $\begin{array}{l}\text { Logaritmo del PIB en EEUU. PIB trimestral EEUU } \\
\text { millones de dólares- base 2000 }\end{array}$ & $\begin{array}{l}\text { U.S. Bureau } \\
\text { of Economic } \\
\text { Analysis (BEA). }\end{array}$ \\
\hline LY & $\begin{array}{l}\text { Logaritmo del PIB en México. PIB trimestral, } \\
\text { millones de dólares base 1993 }\end{array}$ & Banco de México \\
\hline LIED & $\begin{array}{l}\text { Logaritmo de la IED en México. Inversión Extranjera } \\
\text { Directa millones de dólares- base 1980 }\end{array}$ & Banco de México \\
\hline LIPU & $\begin{array}{l}\text { Logaritmo de los precios de EEUU. Inflación EEUU } \\
\text { base 1980 }\end{array}$ & Banco de México \\
\hline LIP & $\begin{array}{l}\text { Logaritmo de los precios de México. Inflación México } \\
\text { base 1980 }\end{array}$ & Banco de México \\
\hline LR & $\begin{array}{l}\text { Logaritmo de las remesas de migrantes en México, } \\
\text { Remesas familiares, millones de dólares base 1980 }\end{array}$ & Banco de México \\
\hline
\end{tabular}




\section{ANEXO 2}

\section{PRINCIPALES ESTUDIOS EMPÍRICOS SOBRE LA RESTRICCIÓN EXTERNA AL CRECIMIENTO DE BALANZA DE PAGOS EN LOS PAÍSES DE AMÉRICA LATINA Y EL CARIBE}

\begin{tabular}{|c|c|c|c|c|c|}
\hline Estudio & Países analizados & Periodo & $\begin{array}{l}\text { Tipo de datos } \\
\text { y técnica } \\
\text { de estimación }\end{array}$ & $\begin{array}{c}\text { Variable } \\
\text { explicada }\end{array}$ & Variables explicativas \\
\hline $\begin{array}{l}\text { Thirlwall y } \\
\text { Hussein (1982) }\end{array}$ & $\begin{array}{l}\text { Honduras, Tailandia, } \\
\text { Chipre, Túnez, } \\
\text { Kenia, Jamaica, } \\
\text { Zaire, Brasil, } \\
\text { Turquía, Sudán, } \\
\text { Marruecos, Pakistán, } \\
\text { Sri Lanka, Costa } \\
\text { Rica, Ecuador, } \\
\text { Filipinas, Colombia, } \\
\text { India, Portugal, } \\
\text { México. }\end{array}$ & $\begin{array}{l}\text { Diversos años, } \\
\text { entre } 1951 \text { y } \\
1976 .\end{array}$ & $\begin{array}{l}\text { Corte Transversal, } \\
\text { MCO }\end{array}$ & $\begin{array}{l}\text { Tasa de } \\
\text { crecimiento } \\
\text { de equilibrio de } \\
\text { balanza } \\
\text { de pagos. }\end{array}$ & $\begin{array}{l}\text { La suma ponderada del } \\
\text { crecimiento de las exportacio- } \\
\text { nes, a causa de un crecimiento } \\
\text { exógeno del ingreso externo } \\
\text { y el crecimiento de los flujos } \\
\text { reales de capital, ambos } \\
\text { divididos por la elasticidad del } \\
\text { ingreso de la demanda de las } \\
\text { importaciones. }\end{array}$ \\
\hline $\begin{array}{l}\text { Guerrero de } \\
\text { Lizardi, (2004) }\end{array}$ & $\begin{array}{l}19 \text { países de Latino- } \\
\text { américa. }\end{array}$ & $\begin{array}{l}1900-2000 \\
\text { Subdividiendo } \\
\text { la muestra en } \\
\text { dos periodos. }\end{array}$ & $\begin{array}{l}\text { Series de Tiempo, } \\
\text { análisis de cointe- } \\
\text { gración. MCO }\end{array}$ & $\begin{array}{l}\text { Tasa de } \\
\text { crecimiento } \\
\text { de equilibrio de } \\
\text { balanza } \\
\text { de pagos. }\end{array}$ & $\begin{array}{l}\text { La ratio de la tasa de cambio } \\
\text { en el volumen de exportaciones } \\
\text { y de la elasticidad ingreso de } \\
\text { la demanda de importaciones, } \\
\text { asumiendo ningún cambio en } \\
\text { los precios de intercambio y el } \\
\text { tipo de cambio. }\end{array}$ \\
\hline $\begin{array}{l}\text { Pacheco-López, } \\
\text { P. \& Thirlwall, } \\
\text { A.P. (2006) }\end{array}$ & $\begin{array}{l}17 \text { países } \\
\text { latinoamericanos. }\end{array}$ & 1977-2002. & $\begin{array}{l}\text { Datos de Panel } \\
\text { y contraste con } \\
\text { Series temporales } \\
\text { de sección } \\
\text { cruzada. }\end{array}$ & $\begin{array}{l}\text { Balanza } \\
\text { comercial/PIB. }\end{array}$ & $\begin{array}{l}\text { Tasa de crecimiento del ingreso } \\
\text { doméstico, tasa de crecimiento } \\
\text { del ingreso externo, tasa de va- } \\
\text { riación del tipo de cambio, y } \\
\text { una dummy que mida el efecto } \\
\text { de la liberalización (con rezagos } \\
\text { de uno y dos periodos). }\end{array}$ \\
\hline CEPAL (2005) & $\begin{array}{l}\text { Países } \\
\text { del CARICOM. }\end{array}$ & 1980-2003 & $\begin{array}{l}\text { Series temporales, } \\
\text { análisis de cointe- } \\
\text { gración. }\end{array}$ & $\begin{array}{l}\text { Tasa de } \\
\text { crecimiento } \\
\text { de equilibrio de } \\
\text { balanza } \\
\text { de pagos. }\end{array}$ & $\begin{array}{l}\text { La suma ponderada del creci- } \\
\text { miento de las exportaciones, a } \\
\text { causa de un crecimiento exóge- } \\
\text { no del ingreso externo y el cre- } \\
\text { cimiento de los flujos reales de } \\
\text { capital, ambos divididos por la } \\
\text { elasticidad del ingreso de la de- } \\
\text { manda de las importaciones }\end{array}$ \\
\hline
\end{tabular}




\section{ANEXO 2 (continuación)}

\section{PRINCIPALES ESTUDIOS EMPÍRICOS SOBRE LA RESTRICCIÓN EXTERNA AL CRECIMIENTO DE BALANZA DE PAGOS EN LOS PAÍSES DE AMÉRICA LATINA Y EL CARIBE}

\begin{tabular}{|c|c|c|}
\hline Principales resultados & Fuente datos & Observaciones \\
\hline $\begin{array}{l}\text { Los resultados empíricos son mixtos para ambos } \\
\text { factores. }\end{array}$ & $\begin{array}{l}\text { M. Khan, (1974), } \\
\text { Houthakker y Magee } \\
\text { (1969). }\end{array}$ & $\begin{array}{l}\text { Dado que en el modelo original de Thirlwall, la } \\
\text { única posibilidad de que la tasa de crecimiento } \\
\text { de una economía se desvié de su senda de largo } \\
\text { plazo es la existencia de cambios en los térmi- } \\
\text { nos de intercambio y/o en los flujos de capital. } \\
\text { El modelo desarrollado considera ésta posibili- } \\
\text { dad para ejemplificar mejor el caso de econo- } \\
\text { mías en desarrollo y observar el papel de los flu- } \\
\text { jos de capital como motor de financiamiento y/o } \\
\text { restricción en su crecimiento. }\end{array}$ \\
\hline $\begin{array}{l}\text { Se obtiene evidencia sobre la relación y depen- } \\
\text { dencia -aunque heterogénea- de las economías } \\
\text { latinoamericanas con la economía de EEUU du- } \\
\text { rante el siglo XX. }\end{array}$ & $\begin{array}{l}\text { Latin American Centre, } \\
\text { Oxford, Bureau } \\
\text { of Economic Analysis; } \\
\text { Angus Maddison } \\
\text { database. }\end{array}$ & $\begin{array}{l}\text { La "ley de Thirlwall" muestra un deterioro en la } \\
\text { relajación de la restricción externa en las mayo- } \\
\text { res economías de la región. Sólo Chile, eviden- } \\
\text { cia un resultado favorable. }\end{array}$ \\
\hline $\begin{array}{l}\text { Se mide el trade-off entre crecimiento y deterioro } \\
\text { comercial en compatibilidad con otros objetivos } \\
\text { macroeconómicos. Chile y Venezuela han logrado } \\
\text { mejorar está relación. Nueve países han crecido } \\
\text { más pero a costa de un mayor déficit y en el resto } \\
\text { no presenta cambio. }\end{array}$ & $\begin{array}{l}\text { Banco Mundial } \\
\text { (WDI, 2004). }\end{array}$ & $\begin{array}{l}\text { Los principales objetivos son medir: el com- } \\
\text { portamiento de la disyuntiva entre crecimiento } \\
\text { y déficit comercial \% PIB en un contexto pre- } \\
\text { apertura y post-apertura (ver si hay o no mejo- } \\
\text { ra), y analizar esta relación mediante un análi- } \\
\text { sis robusto, al introducir variables de control } \\
\text { como son el tipo de cambio y el PIB mundial } \\
\text { en la ecuación básica de trade-off. El resultado } \\
\text { muestra que este mecanismo persiste y se ha } \\
\text { agudizado durante la apertura en la mayoría de } \\
\text { los países. }\end{array}$ \\
\hline $\begin{array}{l}\text { Estos países han intentado superar las restricciones } \\
\text { en BP por medio de la estrategia de atracción de IE } \\
\text { que sin embargo, no han mejorado el desempeño } \\
\text { exportador y si una contracción de la manufactura } \\
\text { y la agricultura, agravando la restricción externa }\end{array}$ & CEPAL & $\begin{array}{l}\text { Incluye una revisión más amplia de los enfoques } \\
\text { de restricción externa al crecimiento que resal- } \\
\text { tan la dificultad en términos de crecimiento para } \\
\text { los países caribeños de haber adoptado una es- } \\
\text { trategia de atracción de IE y de aumento del aho- } \\
\text { rro en la economía }\end{array}$ \\
\hline
\end{tabular}




\begin{tabular}{|c|c|c|c|c|c|}
\hline Estudio & Países analizados & Periodo & $\begin{array}{l}\text { Tipo de datos } \\
\text { y técnica } \\
\text { de estimación }\end{array}$ & $\begin{array}{c}\text { Variable } \\
\text { explicada }\end{array}$ & Variables explicativas \\
\hline Perraton (2003) & 51 países. & 1973-1995 & $\begin{array}{l}\text { Series de Tiempo, } \\
\text { análisis de cointe- } \\
\text { gración. MCO }\end{array}$ & $\begin{array}{l}\text { Tasa de } \\
\text { crecimiento } \\
\text { de equilibrio de } \\
\text { balanza } \\
\text { de pagos. }\end{array}$ & $\begin{array}{l}\text { Elasticidad ingreso de la deman- } \\
\text { da mundial de las exportaciones } \\
\text { de un país. } \\
\text { Elasticidad ingreso demanda de } \\
\text { importaciones. } \\
\text { Funciones de comercio conven- } \\
\text { cionales de Thirlwall. }\end{array}$ \\
\hline $\begin{array}{l}\text { López y Cruz } \\
\text { (2000) }\end{array}$ & $\begin{array}{l}\text { Argentina, Brasil, } \\
\text { Colombia y México. }\end{array}$ & $\begin{array}{l}\text { Mitad 1960- } \\
\text { mitad } 1990\end{array}$ & $\begin{array}{l}\text { Series de Tiempo, } \\
\text { análisis de cointe- } \\
\text { gración. MCO }\end{array}$ & $\begin{array}{l}\text { Tasa de creci- } \\
\text { miento de equi- } \\
\text { librio de balanza } \\
\text { de pagos; } \\
\text { [para verificar el } \\
\text { efecto del tipo de } \\
\text { cambio real: Ba- } \\
\text { lanza comercial] }\end{array}$ & $\begin{array}{l}\text { Elasticidad exportaciones y de } \\
\text { importaciones; } \\
\text { [PIB mundial, PIB doméstico, } \\
\text { tipo de cambio real (en logarit- } \\
\text { mos). }\end{array}$ \\
\hline $\begin{array}{l}\text { Moreno-Brid } \\
\text { y Pérez (1999) }\end{array}$ & $\begin{array}{l}\text { Costa Rica, } \\
\text { El Salvador, } \\
\text { Guatemala, } \\
\text { Honduras } \\
\text { y Nicaragua }\end{array}$ & $1950-1996$ & $\begin{array}{l}\text { Series de Tiempo, } \\
\text { análisis de cointe- } \\
\text { gración. MCO }\end{array}$ & $\begin{array}{l}\text { Tasa de } \\
\text { crecimiento } \\
\text { de equilibrio de } \\
\text { balanza } \\
\text { de pagos. }\end{array}$ & $\begin{array}{l}\text { Tasa de crecimiento de las ex- } \\
\text { portaciones, elasticidad ingreso } \\
\text { de las importaciones y los tér- } \\
\text { minos de intercambio. }\end{array}$ \\
\hline $\begin{array}{l}\text { Cimolli y } \\
\text { Correa (2002) }\end{array}$ & $\begin{array}{l}\text { Argentina, Brasil, } \\
\text { Chile, Colombia, } \\
\text { México, Perú, } \\
\text { Uruguay }\end{array}$ & $\begin{array}{l}(1970-1990) \\
\text { pre-reforma } \\
1991-1999 \\
\text { post-reforma } \\
\text { [varios } \\
\text { subperiodos] }\end{array}$ & $\begin{array}{l}\text { Corte Transversal, } \\
\text { MCO }\end{array}$ & $\begin{array}{l}\text { Tasa de } \\
\text { crecimiento } \\
\text { de equilibrio de } \\
\text { balanza } \\
\text { de pagos. }\end{array}$ & $\begin{array}{l}\text { El multiplicador de comercio y } \\
\text { demanda mundial y elasticidad } \\
\text { ingreso de la demanda de ex- } \\
\text { portaciones. }\end{array}$ \\
\hline $\begin{array}{l}\text { Holland, Vilela } \\
\text { y Canuto } \\
(2004)\end{array}$ & $\begin{array}{l}\text { Argentina, Bolivia, } \\
\text { Brasil, Chile, } \\
\text { Colombia, Ecuador, } \\
\text { México, Perú, } \\
\text { Uruguay, Venezuela }\end{array}$ & $\begin{array}{l}\text { Varios } \\
\text { periodos entre } \\
1951-2000\end{array}$ & $\begin{array}{l}\text { Series de Tiempo, } \\
\text { análisis de cointe- } \\
\text { gración. Análisis } \\
\text { VAR }\end{array}$ & $\begin{array}{l}\text { Tasa de } \\
\text { crecimiento } \\
\text { de equilibrio de } \\
\text { balanza } \\
\text { de pagos. }\end{array}$ & $\begin{array}{l}\text { Elasticidades ingreso demanda } \\
\text { de importaciones y exportacio- } \\
\text { nes. }\end{array}$ \\
\hline $\begin{array}{l}\text { Matesanz, } \\
\text { Fugarolas } \\
\text { y Candaudap } \\
\text { (2007) }\end{array}$ & México y Argentina & $1968-2003$ & \begin{tabular}{l|} 
Análisis \\
multivariante \\
de Cointegración.
\end{tabular} & $\begin{array}{l}\text { Tasa de } \\
\text { crecimiento } \\
\text { de equilibrio de } \\
\text { balanza } \\
\text { de pagos. }\end{array}$ & $\begin{array}{l}\text { Elasticidades ingreso demanda } \\
\text { de importaciones y exportacio- } \\
\text { nes. }\end{array}$ \\
\hline $\begin{array}{l}\text { Averilca y } \\
\text { Risso (2007) }\end{array}$ & Bolivia & $1953-2002$ & $\begin{array}{l}\text { Series de Tiempo, } \\
\text { análisis de cointe- } \\
\text { gración. }\end{array}$ & $\begin{array}{l}\text { Tasa de } \\
\text { crecimiento } \\
\text { de equilibrio de } \\
\text { balanza } \\
\text { de pagos. }\end{array}$ & $\begin{array}{l}\text { Elasticidades ingreso demanda } \\
\text { de importaciones y exportacio- } \\
\text { nes, y el tipo de cambio real. }\end{array}$ \\
\hline
\end{tabular}




\begin{tabular}{|c|c|c|}
\hline Principales resultados & Fuente datos & Observaciones \\
\hline $\begin{array}{l}\text { La estimación de las funciones de comercio y las } \\
\text { elasticidades resultantes muestran que solo es po- } \\
\text { sible obtener valores estables para } 27 \text { países. A pe- } \\
\text { sar de ello y apoyándose en las estimaciones elas- } \\
\text { ticidad ingreso de Senhadji (1998). Se obtiene un } \\
\text { buen ajuste entre la tasa de crecimiento de equili- } \\
\text { brio estimada y la real. }\end{array}$ & $\begin{array}{l}\text { World Bank, World } \\
\text { Development Indicators } \\
1997 \text { CD-ROM. } \\
\text { IMF, International } \\
\text { Financial Statistics } \\
\text { Yearbook, 1997. }\end{array}$ & $\begin{array}{l}\text { A pesar de que los resultados muestran que la } \\
\text { desviación entre la tasa de crecimiento estima- } \\
\text { da y la real está poco influida por los flujos de } \\
\text { capital, el autor considera relevante hacer énfa- } \\
\text { sis en la calidad de los datos para los países en } \\
\text { desarrollo y considerarlo en la interpretación } \\
\text { final. }\end{array}$ \\
\hline $\begin{array}{l}\text { El crecimiento del producto muestra una relación } \\
\text { estrecha con el crecimiento de las exportaciones } \\
\text { en el largo plazo; además de que mayores expor- } \\
\text { taciones tienden a causar mayor crecimiento. El } \\
\text { papel del tipo de cambio real es relevante en la } \\
\text { determinación del equilibrio externo. }\end{array}$ & $\begin{array}{l}\text { International Statistics } \\
\text { Yearbook FMI, 1995, } \\
1996 .\end{array}$ & $\begin{array}{l}\text { La condición Marshall-Lerner muestra no se sa- } \\
\text { tisface en el caso de Brasil y México. Argentina, } \\
\text { lo cumple aunque en esta última la asociación } \\
\text { tipo de cambio y la producción es negativa, por } \\
\text { un posible efecto nocivo de un alto tipo de cam- } \\
\text { bio real sobre la demanda interna. }\end{array}$ \\
\hline $\begin{array}{l}\text { Fuerte asociación entre la tasa de crecimiento real } \\
\text { del PIB con las exportaciones reales y los términos } \\
\text { de intercambio, (con preponderancia de la prime- } \\
\text { ra). Se confirma lo anterior para Costa Rica, Gua- } \\
\text { temala y Nicaragua. }\end{array}$ & CEPAL (varios años) & $\begin{array}{l}\text { El Salvador y Honduras no cumplen con el mo- } \\
\text { delo básico, por lo que el ampliado a la inclusión } \\
\text { de flujos de capital, podría explicar mejor su di- } \\
\text { námica de crecimiento. Lo anterior lo atribuyen } \\
\text { los autores al papel que ha tenido en estos paí- } \\
\text { ses los flujos de remesas de migrantes y la ayu- } \\
\text { da oficial. }\end{array}$ \\
\hline $\begin{array}{l}\text { Los países han cerrado expandido lentamente sus } \\
\text { sectores de exportación. La reducción se ha conse- } \\
\text { guido sin compensar el fuerte incremento de la elas- } \\
\text { ticidad de la demanda de las importaciones por lo } \\
\text { que el multiplicador de comercio ha declinado en- } \\
\text { tre periodos de estudio. }\end{array}$ & CEPAL & $\begin{array}{l}\text { La tasa de crecimiento actual es mayor a la de } \\
\text { equilibrio de Balanza de Pagos en un contexto } \\
\text { de reducción de superávit e incremento de los } \\
\text { déficit. }\end{array}$ \\
\hline $\begin{array}{l}\text { Se confirma la fuerte asociación entre el creci- } \\
\text { miento del PIB y comercio. Los resultados mues- } \\
\text { tras que países con acelerada tasa de crecimiento } \\
\text { de largo plazo son compatibles con la condición de } \\
\text { equilibrio en BP, excepto México. }\end{array}$ & FMI & $\begin{array}{l}\text { Se considera la necesidad de profundizar en el } \\
\text { análisis del tipo de cambio, los términos de in- } \\
\text { tercambio y los flujos de capital. }\end{array}$ \\
\hline $\begin{array}{l}\text { Se contrasta la validez de la ley de Thirlwall para } \\
\text { explicar el periodo de estudio, en los dos países, } \\
\text { caracterizado por crisis recientes. Por un breve } \\
\text { periodo posterior a las crisis ambos países crecían } \\
\text { por arriba de su restricción externa. }\end{array}$ & FMI y CEPAL & $\begin{array}{l}\text { Se sugiere profundizar el análisis a fin de estu- } \\
\text { diar el efecto de los servicios en las funciones de } \\
\text { comercio. }\end{array}$ \\
\hline $\begin{array}{l}\text { Se confirma que las exportaciones han sido deter- } \\
\text { minantes para explicar la dinámica de crecimiento } \\
\text { de la economía. Sin embargo el tipo de cambio } \\
\text { guarda una relación negativa con el crecimiento de } \\
\text { largo plazo. }\end{array}$ & $\begin{array}{l}\text { World Development } \\
\text { Indicators, CEPAL, } \\
\text { OXLAD }\end{array}$ & $\begin{array}{l}\text { De acuerdo con los resultados se afirma que el } \\
\text { país ha experimentado un proceso de desindus- } \\
\text { trialización después de } 1985 .\end{array}$ \\
\hline
\end{tabular}




\begin{tabular}{|c|c|c|c|c|c|}
\hline Estudio & Países analizados & Periodo & $\begin{array}{l}\text { Tipo de datos } \\
\text { y técnica } \\
\text { de estimación }\end{array}$ & $\begin{array}{l}\text { Variable } \\
\text { explicada }\end{array}$ & Variables explicativas \\
\hline $\begin{array}{l}\text { Fugarolas } \\
\text { y Matesanz } \\
(2005)\end{array}$ & Argentina & $1968-2003$ & $\begin{array}{l}\text { Series de Tiempo, } \\
\text { análisis de cointe- } \\
\text { gración. }\end{array}$ & $\begin{array}{l}\text { Tasa de } \\
\text { crecimiento } \\
\text { de equilibrio de } \\
\text { balanza } \\
\text { de pagos. }\end{array}$ & $\begin{array}{l}\text { Elasticidades ingreso demanda } \\
\text { de importaciones y exportacio- } \\
\text { nes. }\end{array}$ \\
\hline Brito (2008) & Brasil & $1951-2006$ & $\begin{array}{l}\text { Series de Tiempo, } \\
\text { análisis de cointe- } \\
\text { gración. }\end{array}$ & $\begin{array}{l}\text { Tasa de } \\
\text { crecimiento } \\
\text { de equilibrio de } \\
\text { balanza } \\
\text { de pagos. }\end{array}$ & $\begin{array}{l}\text { Elasticidades ingreso demanda } \\
\text { de importaciones y exportacio- } \\
\text { nes y flujos netos de capital } \\
\text { (modelo de Thirlwall } \\
\text { ampliado). }\end{array}$ \\
\hline $\begin{array}{l}\text { Vidal } \\
\text { y Fundora } \\
(2008)\end{array}$ & Cuba & $\begin{array}{l}1950-2005 \\
\text { y subperiodos }\end{array}$ & Filtro de Kaufman & $\begin{array}{l}\text { Tasa de } \\
\text { crecimiento } \\
\text { de equilibrio de } \\
\text { balanza } \\
\text { de pagos. }\end{array}$ & $\begin{array}{l}\text { Términos de intercambio, } \\
\text { financiamiento externo } \\
\text { y exportaciones (modelo } \\
\text { ampliado Thirlwall y Hussein). }\end{array}$ \\
\hline $\begin{array}{l}\text { Pardo y Reig } \\
\text { (2002) }\end{array}$ & Uruguay & 1960-2002 & $\begin{array}{l}\text { Series de Tiempo, } \\
\text { análisis de cointe- } \\
\text { gración. }\end{array}$ & $\begin{array}{l}\text { Tasa de } \\
\text { crecimiento } \\
\text { de equilibrio de } \\
\text { balanza } \\
\text { de pagos. }\end{array}$ & $\begin{array}{l}\text { Elasticidades ingreso demanda } \\
\text { de importaciones y exportacio- } \\
\text { nes y flujos de capital (modelos } \\
\text { básico y ampliado). }\end{array}$ \\
\hline $\begin{array}{l}\text { Gonzaga } \\
(2003)\end{array}$ & Brasil & 1955-1998 & $\begin{array}{l}\text { Series de Tiempo, } \\
\text { análisis de } \\
\text { cointegración y la } \\
\text { técnica del vector } \\
\text { de corrección de } \\
\text { errores. }\end{array}$ & $\begin{array}{l}\text { Tasa de } \\
\text { crecimiento } \\
\text { de equilibrio de } \\
\text { balanza } \\
\text { de pagos. }\end{array}$ & $\begin{array}{l}\text { Tasa de crecimiento de las } \\
\text { exportaciones, elasticidad } \\
\text { ingreso de las importaciones } \\
\text { y las exportaciones, y flujos } \\
\text { netos de capital. }\end{array}$ \\
\hline Velasco (2006) & Colombia & $1925-2000$ & $\begin{array}{l}\text { Series de Tiempo, } \\
\text { análisis de cointe- } \\
\text { gración. }\end{array}$ & $\begin{array}{l}\text { Tasa de } \\
\text { crecimiento } \\
\text { de equilibrio de } \\
\text { balanza } \\
\text { de pagos. }\end{array}$ & $\begin{array}{l}\text { Tasa de crecimiento de las } \\
\text { exportaciones, elasticidad } \\
\text { ingreso de las importaciones } \\
\text { y las exportaciones, y flujos } \\
\text { netos de capital. }\end{array}$ \\
\hline $\begin{array}{l}\text { Velastegui } \\
\text { (2007) }\end{array}$ & Ecuador & 1970-2004 & $\begin{array}{l}\text { Series de Tiempo, } \\
\text { análisis de cointe- } \\
\text { gración. }\end{array}$ & $\begin{array}{l}\text { Tasa de } \\
\text { crecimiento } \\
\text { de equilibrio de } \\
\text { balanza } \\
\text { de pagos. }\end{array}$ & $\begin{array}{l}\text { Tasa de crecimiento de las } \\
\text { exportaciones, elasticidad } \\
\text { ingreso de las importaciones } \\
\text { y las exportaciones } \\
\text { (modelo básico). }\end{array}$ \\
\hline $\begin{array}{l}\text { García } \\
\text { y Quevedo } \\
(2005)\end{array}$ & Colombia & $1952-2000$ & $\begin{array}{l}\text { Series de Tiempo, } \\
\text { análisis de cointe- } \\
\text { gración. Análisis } \\
\text { VAR }\end{array}$ & $\begin{array}{l}\text { Tasa de } \\
\text { crecimiento } \\
\text { de equilibrio de } \\
\text { balanza } \\
\text { de pagos. }\end{array}$ & $\begin{array}{l}\text { Elasticidades ingreso demanda } \\
\text { de importaciones y exportacio- } \\
\text { nes, y el tipo de cambio real. }\end{array}$ \\
\hline
\end{tabular}




\begin{tabular}{|c|c|c|}
\hline Principales resultados & Fuente datos & Observaciones \\
\hline $\begin{array}{l}\text { Las tasas de crecimiento teóricas son consistentes } \\
\text { con las reales en todo el periodo analizado. }\end{array}$ & FMI e INDEC & $\begin{array}{l}\text { El débil crecimiento de Argentina se atribuye al } \\
\text { estancamiento de su sector exportador posterior } \\
\text { a los años setenta. }\end{array}$ \\
\hline $\begin{array}{l}\text { El modelo ampliado de Thirlwall por Moreno- } \\
\text { Brid confirma el papel relevante de los flujos de } \\
\text { capital. }\end{array}$ & Banco Central de Brasil & $\begin{array}{l}\text { Existe una senda de crecimiento de largo plazo } \\
\text { que es compatible con el equilibrio externo de } \\
\text { balanza de pagos. }\end{array}$ \\
\hline $\begin{array}{l}\text { Las exportaciones reales han tenido el mayor peso } \\
\text { relativo en el PIB, desempeñando un papel dina- } \\
\text { mizador en el crecimiento después de la crisis, a pe- } \\
\text { sar de la mayor elasticidad ingreso de las importa- } \\
\text { ciones. }\end{array}$ & $\begin{array}{l}\text { Oficina Nacional } \\
\text { de Estadísticas de Cuba } \\
\text { y el Instituto Nacional de } \\
\text { Investigación Económica. }\end{array}$ & $\begin{array}{l}\text { A causa de la insuficiente oferta interna de } \\
\text { bienes intermedios y de capital, el crecimiento } \\
\text { está estrechamente vinculado con las importa- } \\
\text { ciones. }\end{array}$ \\
\hline $\begin{array}{l}\text { La evidencia empírica sugieren la validez de la ley } \\
\text { de Thirlwall para la economía uruguaya en el pe- } \\
\text { ríodo de estudio, así como que los flujos netos rea- } \\
\text { les de capital tuvieron una escasa participación en } \\
\text { el financiamiento de la balanza de pagos. }\end{array}$ & $\begin{array}{l}\text { Banco Central } \\
\text { de Uruguay }\end{array}$ & $\begin{array}{l}\text { No se descartan fricciones desde el lado de la } \\
\text { oferta. }\end{array}$ \\
\hline Se va validez a la ley de Thirlwall. & Banco Central de Brasil & $\begin{array}{l}\text { A pesar de que se resalta que para lograr el cre- } \\
\text { cimiento sustentable se debe dar énfasis a la } \\
\text { parte tecnológica e institucional, el modelo no } \\
\text { incorpora alguna variable de este tipo. }\end{array}$ \\
\hline $\begin{array}{l}\text { La ley de Thirlwall sólo se cumple para periodos } \\
\text { cortos. Para periodos largos la regla simple no se } \\
\text { verifica. El papel de la deuda y la volatilidad tie- } \\
\text { nen un peso relativo para explicar la dinámica de } \\
\text { crecimiento reciente. }\end{array}$ & Banco de la República & $\begin{array}{l}\text { De acuerdo con el análisis de las hipótesis de } \\
\text { la regla simple, el cambio en el patrón de es- } \\
\text { pecialización externa y en la estructura de im- } \\
\text { portaciones comienza a mediados de los años } \\
\text { ochenta. }\end{array}$ \\
\hline Se sugiere la validez de la ley de Thirlwall & Banco Central de Ecuador & \\
\hline $\begin{array}{l}\text { La ley de Thirlwall se verifica para Colombia en el } \\
\text { periodo 1950-2000 (a pesar de que no cumplirse } \\
\text { para algunos periodos) }\end{array}$ & Banco de la República & $\begin{array}{l}\text { La tasa de cambio tiene un papel importante so- } \\
\text { bre la tasa de crecimiento de largo plazo. }\end{array}$ \\
\hline
\end{tabular}




\begin{tabular}{|c|c|c|c|c|c|}
\hline Estudio & Países analizados & Periodo & $\begin{array}{l}\text { Tipo de datos } \\
\text { y técnica } \\
\text { de estimación }\end{array}$ & $\begin{array}{c}\text { Variable } \\
\text { explicada }\end{array}$ & Variables explicativas \\
\hline $\begin{array}{l}\text { Parikh y Stirbu } \\
(2004)\end{array}$ & $\begin{array}{l}42 \text { países en } 3 \text { regio- } \\
\text { nes: África, Asia } \\
\text { y Latinoamérica. }\end{array}$ & 1970-1999 & $\begin{array}{l}\text { Datos en Panel: } \\
\text { Efectos fijos y }\end{array}$ & $\begin{array}{l}\text { Tasa de creci- } \\
\text { miento; Balanza } \\
\text { Comercial/PIB; } \\
\text { Cuenta } \\
\text { Corriente/PIB }\end{array}$ & $\begin{array}{l}\text { Se adaptan los modelos de REC } \\
\text { para captar el papel del tipo } \\
\text { de cambio, multiplicador de } \\
\text { Harrod y modelo ampliado de } \\
\text { Thirlwall y Hussein. }\end{array}$ \\
\hline $\begin{array}{l}\text { Moreno-Brid } \\
\text { (2003) }\end{array}$ & México. & 1967-1999 & $\begin{array}{l}\text { Series de Tiempo, } \\
\text { análisis de cointe- } \\
\text { gración. MCO }\end{array}$ & $\begin{array}{l}\% \text { tasa de } \\
\text { Crecimiento } \\
\text { del PIB }\end{array}$ & $\begin{array}{l}\text { Se realizan } 3 \text { pruebas. } \\
\text { (1) modelo básico de Thirlwall; } \\
\text { (2) modelo extendido de } \\
\text { Thirlwall con endeudamiento } \\
\text { externo y } \\
\text { (3) modelo extendido con } \\
\text { endeudamiento considerando } \\
\text { la influencia del pago } \\
\text { de intereses externos. }\end{array}$ \\
\hline $\begin{array}{l}\text { Moreno-Brid } \\
\text { (1999) }\end{array}$ & México. & $\begin{array}{l}\text { 1950-1996. } \\
\text { (subperiodos): } \\
\text { 1950-1981; } \\
1982-1996\end{array}$ & $\begin{array}{l}\text { Series de Tiempo, } \\
\text { análisis de cointe- } \\
\text { gración. MCO }\end{array}$ & $\begin{array}{l}\% \text { tasa de } \\
\text { Crecimiento } \\
\text { del PIB }\end{array}$ & $\begin{array}{l}\text { La ratio de la tasa de cambio } \\
\text { en el volumen de exportaciones } \\
\text { y de la elasticidad ingreso de la } \\
\text { demanda de importaciones. }\end{array}$ \\
\hline $\begin{array}{l}\text { Loría, E. } \\
(2001)\end{array}$ & México & 1970-1999 & $\begin{array}{l}\text { Series de Tiempo, } \\
\text { análisis de cointe- } \\
\text { gración. MCO }\end{array}$ & $\begin{array}{l}\% \text { tasa de } \\
\text { Crecimiento } \\
\text { del PIB }\end{array}$ & $\begin{array}{l}\text { La ratio de la tasa de cambio } \\
\text { en el volumen de exportaciones } \\
\text { y de la elasticidad ingreso de la } \\
\text { demanda de importaciones. }\end{array}$ \\
\hline $\begin{array}{l}\text { Loría, E. } \\
(2003)\end{array}$ & México & 1970-1999 & $\begin{array}{l}\text { Simultaneous } \\
\text { equations } \\
\text { (weighted two } \\
\text { least squares) }\end{array}$ & $\begin{array}{l}\text { Un primer } \\
\text { objetivo } \\
\text { es la Cuenta } \\
\text { Corriente } \\
\text { de la Balanza } \\
\text { de Pagos, } \\
\text { en tanto un } \\
\text { segundo } \\
\text { es determinar } \\
\text { el tipo de } \\
\text { cambio real. }\end{array}$ & $\begin{array}{l}\text { Balanza Comercial, balanza } \\
\text { de Servicios no factoriales, } \\
\text { balanza de servicios factoriales } \\
\text { y balanza de transferencias. } \\
\text { Todo ello modelizado } \\
\text { en ocho ecuaciones } \\
\text { de comportamiento, } \\
3 \text { identidades contables, } \\
17 \text { variables exógenas } \\
\text { y } 7 \text { variables endógenas } \\
\text { predeterminadas. }\end{array}$ \\
\hline
\end{tabular}




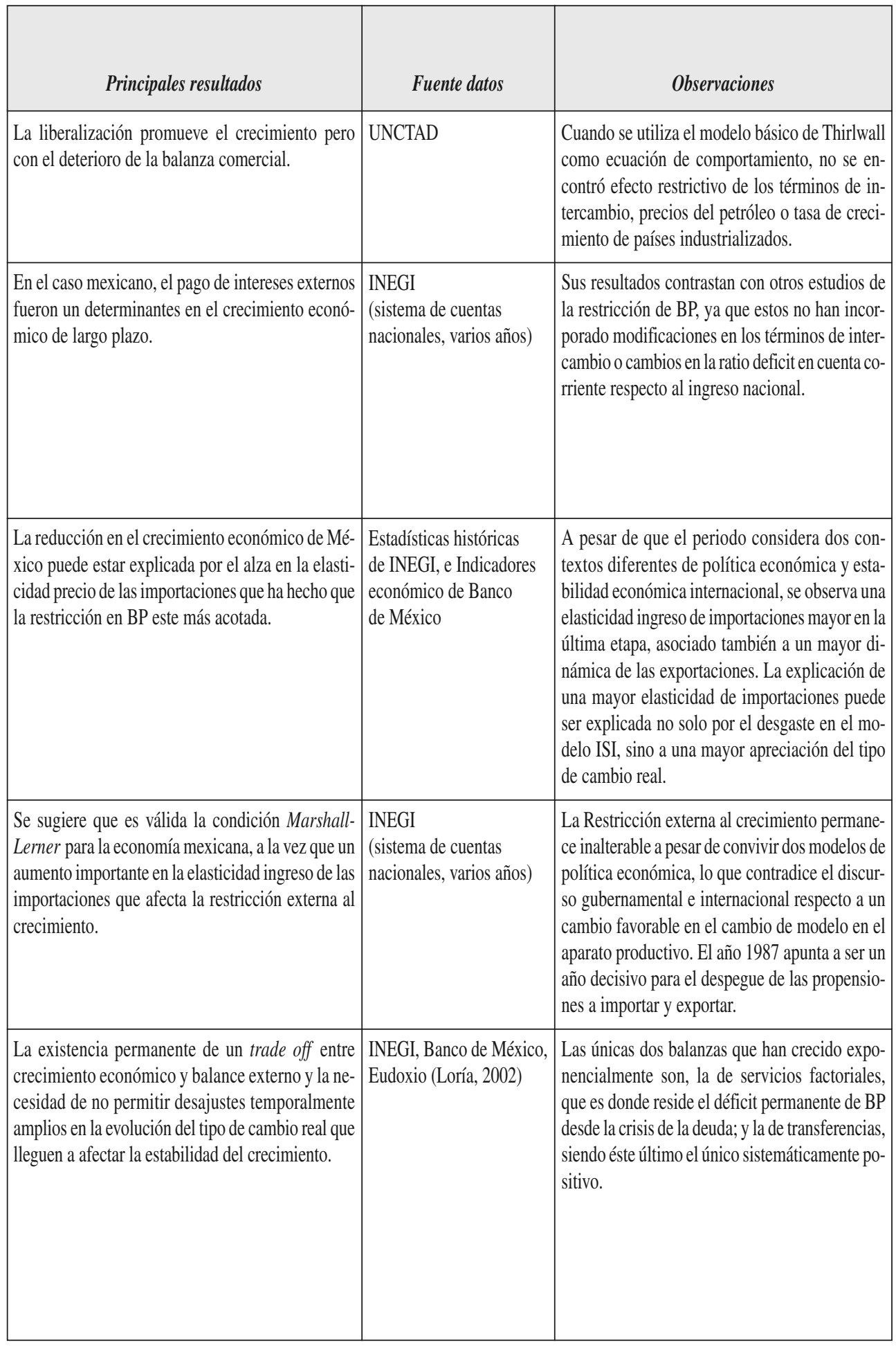




\begin{tabular}{|l|l|l|l|l|l|}
\hline \multicolumn{1}{|c|}{ Estudio } & Países analizados & Periodo & $\begin{array}{c}\text { Tipo de datos } \\
\text { y técnica } \\
\text { de estimación }\end{array}$ & \multicolumn{1}{c|}{$\begin{array}{c}\text { Variable } \\
\text { explicada }\end{array}$} & \multicolumn{1}{c|}{ Variables explicativas } \\
\hline $\begin{array}{l}\text { Loría, E. } \\
\text { \& Fujii, G. } \\
\text { (1997) }\end{array}$ & México & $1950-1996$ & $\begin{array}{l}\text { Análisis } \\
\text { descriptivo }\end{array}$ & $\begin{array}{l}\text { Balanza } \\
\text { comercial }\end{array}$ & $\begin{array}{l}\text { Coeficientes de importación en } \\
\text { la manufactura, nueva política } \\
\text { macroeconómica, estructura de } \\
\text { mercado con escasos vínculos } \\
\text { productivos y exportaciones no } \\
\text { manufactureros. }\end{array}$ \\
\hline $\begin{array}{l}\text { Lizardi, G. } \\
\text { (2007) }\end{array}$ & México & $1986-2003$ & $\begin{array}{l}\text { Series de Tiempo, } \\
\text { análisis de cointe- } \\
\text { gración. } \\
\text { Metodología VAR }\end{array}$ & $\begin{array}{l}\text { Tasa de } \\
\text { crecimiento } \\
\text { de equilibrio de } \\
\text { balanza } \\
\text { de pagos. }\end{array}$ & $\begin{array}{l}\text { Elasticidad ingreso de las im- } \\
\text { portaciones y elasticidad precio } \\
\text { de las exportaciones, y flujos } \\
\text { netos de capital, ingreso exter- } \\
\text { no. }\end{array}$ \\
\hline $\begin{array}{l}\text { Ocegueda } \\
\text { H. M. (2003) }\end{array}$ & México & $1970-2000$ & $\begin{array}{l}\text { Series de tiempo, } \\
\text { análisis de cointe- } \\
\text { gración }\end{array}$ & $\begin{array}{l}\text { Tasa de } \\
\text { crecimiento } \\
\text { de equilibrio } \\
\text { comercial. }\end{array}$ & $\begin{array}{l}\text { Elasticidad precio de las expor- } \\
\text { taciones e importaciones, tipo } \\
\text { cambio nominal, precios exter- } \\
\text { nos, precios internos e ingreso } \\
\text { externo. }\end{array}$ \\
\hline
\end{tabular}




\begin{tabular}{|l|l|l|}
\hline \multicolumn{1}{|c|}{ Principales resultados } & \multicolumn{1}{|c|}{ Fuente datos } & \multicolumn{1}{c|}{ Observaciones } \\
\hline $\begin{array}{l}\text { A pesar del fuerte cambio en la estructura exporta- } \\
\text { dora hacia bienes manufacturados, la oferta neta de } \\
\text { divisas sigue centrada en exportaciones de petróleo } \\
\text { y otros productos primarios de bajo valor agrega- } \\
\text { do. Existe un marcado incremento de los coefi- } \\
\text { cientes de importación en las ramas exportadores } \\
\text { exitosos. }\end{array}$ & $\begin{array}{l}\text { INEGI Banco de México } \\
\text { y la un de un boom exportador hay evidencias } \\
\text { res de la industria manufacturera, así como una } \\
\text { reducción en los vínculos intersectoriales. Esto } \\
\text { ha llevado a un dramático déficit comercial en el } \\
\text { sector manufacturero que evidencia la verda- } \\
\text { dera restricción externa. El nuevo patrón co- } \\
\text { mercial -que realza el comercio intrafirma- ha } \\
\text { conducido a bajos efectos derrame en la econo- } \\
\text { mía. Por tanto, evidencia la urgencia de una po- } \\
\text { lítica industrial estratégica. }\end{array}$ \\
\hline $\begin{array}{l}\text { Existe una evidencia favorable del modelo post- } \\
\text { keynesiano al caso mexicano en donde los flujos } \\
\text { de capital externo han desempeñado un papel po- } \\
\text { sitivo aunque sigue teniendo un impacto muy re- } \\
\text { ducido. }\end{array}$ & $\begin{array}{l}\text { Dornbusch y Werner } \\
\text { (1994), Loría (2001), } \\
\text { Garcés (2003) e INEGI }\end{array}$ & $\begin{array}{l}\text { Aunque se reconoce el papel del lado de la ofer- } \\
\text { ta no se incluye ninguna variable. }\end{array}$ \\
\hline $\begin{array}{l}\text { El análisis a nivel sectorial dentro de las principa- } \\
\text { les industrias muestra la elevada elasticidad in- } \\
\text { greso demanda de importaciones y el rápido creci- } \\
\text { miento de sus importaciones impiden que mejoren } \\
\text { las condiciones estructurales de la balanza comer- } \\
\text { cial. }\end{array}$ & $\begin{array}{l}\text { INEGI, Bureau of Labor } \\
\text { Statistics, US; FMI }\end{array}$ & \\
\hline
\end{tabular}


